NBER WORKING PAPER SERIES

\title{
CAN POLICY INTERACT WITH CULTURE? MINIMUM WAGE AND THE QUALITY OF LABOR RELATIONS
}

\author{
Philippe Aghion \\ Yann Algan \\ Pierre Cahuc \\ Working Paper 14327 \\ http://www.nber.org/papers/w14327
NATIONAL BUREAU OF ECONOMIC RESEARCH
1050 Massachusetts Avenue
Cambridge, MA 02138 \\ September 2008
}

The authors thank for their very useful comments Daron Acemoglu, Marios Angeletos, Philippe Askenazy, Olivier Blanchard, Daniel Cohen, Jean-Michel Grandmont, Guy Laroque, Etienne Lehmann, Torsten Persson, Thomas Piketty, Guido Tabellini and Andrei Shleifer. We have benefited from many helpful comments from seminar participants at Bocconi, Boston College, CREST, Hebrew University, Mannheim University, MIT, Paris School of Economics, University of Florida and the IOG (Institution, Organization and Growth) group at the Canadian Institute for Advanced Research. The views expressed herein are those of the author(s) and do not necessarily reflect the views of the National Bureau of Economic Research.

(C) 2008 by Philippe Aghion, Yann Algan, and Pierre Cahuc. All rights reserved. Short sections of text, not to exceed two paragraphs, may be quoted without explicit permission provided that full credit, including $\odot$ notice, is given to the source. 
Can Policy Interact with Culture? Minimum Wage and the Quality of Labor Relations

Philippe Aghion, Yann Algan, and Pierre Cahuc

NBER Working Paper No. 14327

September 2008

JEL No. J01,J3

\begin{abstract}
$\underline{\text { ABSTRACT }}$
Can public policy interfere with culture, such as beliefs and norms of cooperation? We investigate this question by evaluating the interactions between the State and the Civil Society, focusing on the labor market. International data shows a negative correlation between union density and the quality of labor relations on one hand, and state regulation of the minimum wage on the other hand. To explain this relation, we develop a model of learning of the quality of labor relations. State regulation crowds out the possibility for workers to experiment negotiation and learn about the true cooperative nature of participants in the labor market. This crowding out effect can give rise to multiple equilibria: a "good" equilibrium characterized by strong beliefs in cooperation, leading to high union density and low state regulation; and a "bad" equilibrium, characterized by distrustful labor relations, low union density and strong state regulation of the minimum wage. We then use surveys on social attitudes and unionization behavior to document the relation between minimum wage legislation and the beliefs about the scope of cooperation in the labor market.
\end{abstract}

\author{
Philippe Aghion \\ Department of Economics \\ Harvard University \\ 1805 Cambridge St \\ Cambridge, MA 02138 \\ and NBER \\ paghion@fas.harvard.edu \\ Yann Algan \\ Sciences Po, OFCE \\ 27 Rue Saint-Guillaume \\ 75007 Paris, France \\ yann.algan@sciences-po.org
}

Pierre Cahuc

École Polytechnique

91128 Palaiseau Cedex, France

cahuc@ensae.fr 


\section{Introduction}

The role of social capital in explaining economic outcomes is gaining wider acceptance among economists. Defined by Putnam (2000), one of the founding father of this concept, as "the collective values of all social networks and the inclinations that arise from these networks to do things for each other", social capital has been found to have a significant effect on growth (Knack and Keefer, 1997, Tabellini, 2005, Algan and Cahuc, 2007), employment (Blanchard and Philippon, 2006), financial development (Guiso et al., 2004) or institutions (La Porta et al., 1997, Algan and Cahuc, 2006, Tabellini, 2007a). ${ }^{1}$ If social capital does play a key role in the economy, it is important to understand how it can be affected by public policies. From this perspective, our paper aims at explaining the interaction between state regulation and social capital, focusing on the labor market.

More specifically, we provide evidence for and then rationalize the existence of a negative relationship between state regulation of minimum wages on the one hand, and both unionization rates and the quality of labor relations, which, as we argue, reflects two-sided causality links between state intervention and investment in social capital. Namely, stringent minimum wage regulations discourage social investments in labor relations and unionization. At the same time low investments in labor relations and/or the resulting low unionization rates, encourage democratic governments to set more stringent minimum wage policies to protect the median voter.

Figure 1 illustrates the negative correlation between the stringency of minimum wage regulations and the level of trust in labor relationships. Figure 2 shows the strong positive correlation between unionization rates and the the level of trust in labor relationships. The index of perceived cooperation on the labor market is constructed using the 1999 Global Competitiveness Reports, a survey sent out to thousands of executives each year with the following question: "Do you think that labor/employer relations are generally cooperative". Responses may vary from 1 for strong disagreement to 7 for strong agreement. ${ }^{2}$ State intervention is then measured by the state's propensity to directly regulate minimum wages instead of letting wage floors be negotiated between employers and employees' unions. The index of state regulation of wage encapsulates : (i) a dummy for the existence of a legal statutory minimum wage in the country; (ii) the ratio of the minimum wage to the median wage; (iii) a dummy for the existence of potential derogations from the law, such as the provision of sub-minimum wages for certain categories; (iv) and a dummy for the existence of legal extensions of minimum wages set by

\footnotetext{
${ }^{1}$ For a synthesis, see Guiso et al. (2006).

${ }^{2}$ Evidence about the perceptions of the quality of labor relations across OECD countries are given each year by the Global Competitiveness Reports. This index is presented more precisely in Section 3.
} 
collective agreements. The data on minimum wages and unionization rates are country average over the period 1980-2003. ${ }^{3}$

Figure 1 and 2 show that Scandinavian countries are characterized by a low level of state intervention in the regulation of minimum wage. Wage floors are directly negotiated between unions and no statutory legal minimum wage exists. This characteristic is associated with highly cooperative labor relations. At the other extreme, state intervention is high in countries (in particular, France) where labor relations are distrustful. Another interesting fact about labor markets comes out of Figure 2. Indeed this figure reports a strong positive correlation between the executives' beliefs in cooperative labor relations and union membership. This directly contradicts a common wisdom whereby anything that strengthens employees' bargaining power in firms, in particular higher rates of unionization, should be negatively perceived by employers and therefore increase their distrust vis-a-vis workers. Countries with low union density, such as France, are characterized by distrustful labor relations, whereas Nordic countries with their high unionization rates show widespread beliefs in cooperative labor relations.

To rationalize these facts and understand the causal relationships between minimum wage regulations and cooperation in labor markets, we develop a model of the labor market where employees can learn about the scope for cooperation with firms through social experimentation. ${ }^{4}$ The effects of state regulation of minimum wages on social capital in our model are similar to those identified by the political science literature on centralized rules regulating the civil society (Ostrom, 2005). First, high legal minimum wage directly reduces the incentives to become a union member: it is not worth paying the cost of union membership when the worker can rely on state regulation (Checchi and Lucifora, 2002). Second, a high legal minimum wage policy erodes social capital in the future: by discouraging individual agents from experimenting collective action and social dialogue, it makes it more difficult for them to learn over time about the scope for cooperation. This in turn crowds out investment in social capital.

Our theoretical argument goes beyond unions and wage regulations. Spending time in associations, investing in negotiation and cooperation, makes it possible for individuals to gather information about the true cooperative nature of other participants in the labor market. This view of learning and cooperation-building is quite in line with Tocqueville's description of associations $^{5}$ as small social laboratories for experimenting cooperation and building up democracy. This representation is also similar to the idea conveyed by Freeman and Medoff (1984) that unions might improve the quality of labor relation by fostering voice rather than exit in in-

\footnotetext{
${ }^{3}$ This index and the definition of union density are presented more precisely in section 3 .

${ }^{4}$ Our model builds on seminal contributions by Piketty (1995), Benabou and Tirole (2006) and Alesina and Angeletos (2005) who use a Bayesian setting to explore the interactions between public policies and beliefs.

${ }^{5}$ See Tocqueville, Democracy in America (1835).
} 


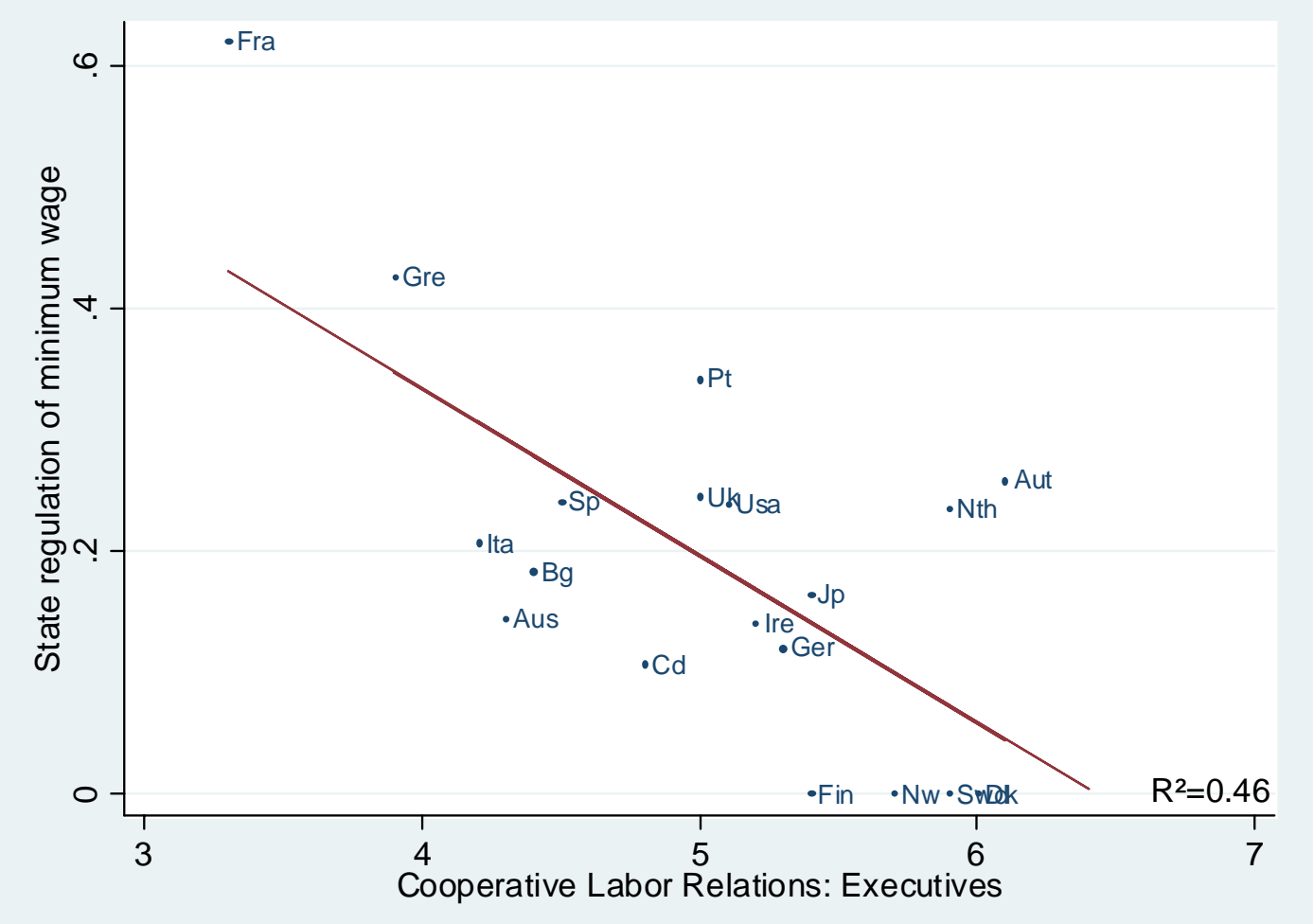

Figure 1: Correlation between State regulation of minimum wages and Executives' beliefs in Cooperative labor relations. Source: ILO, OECD, and GRC 1999 database. 


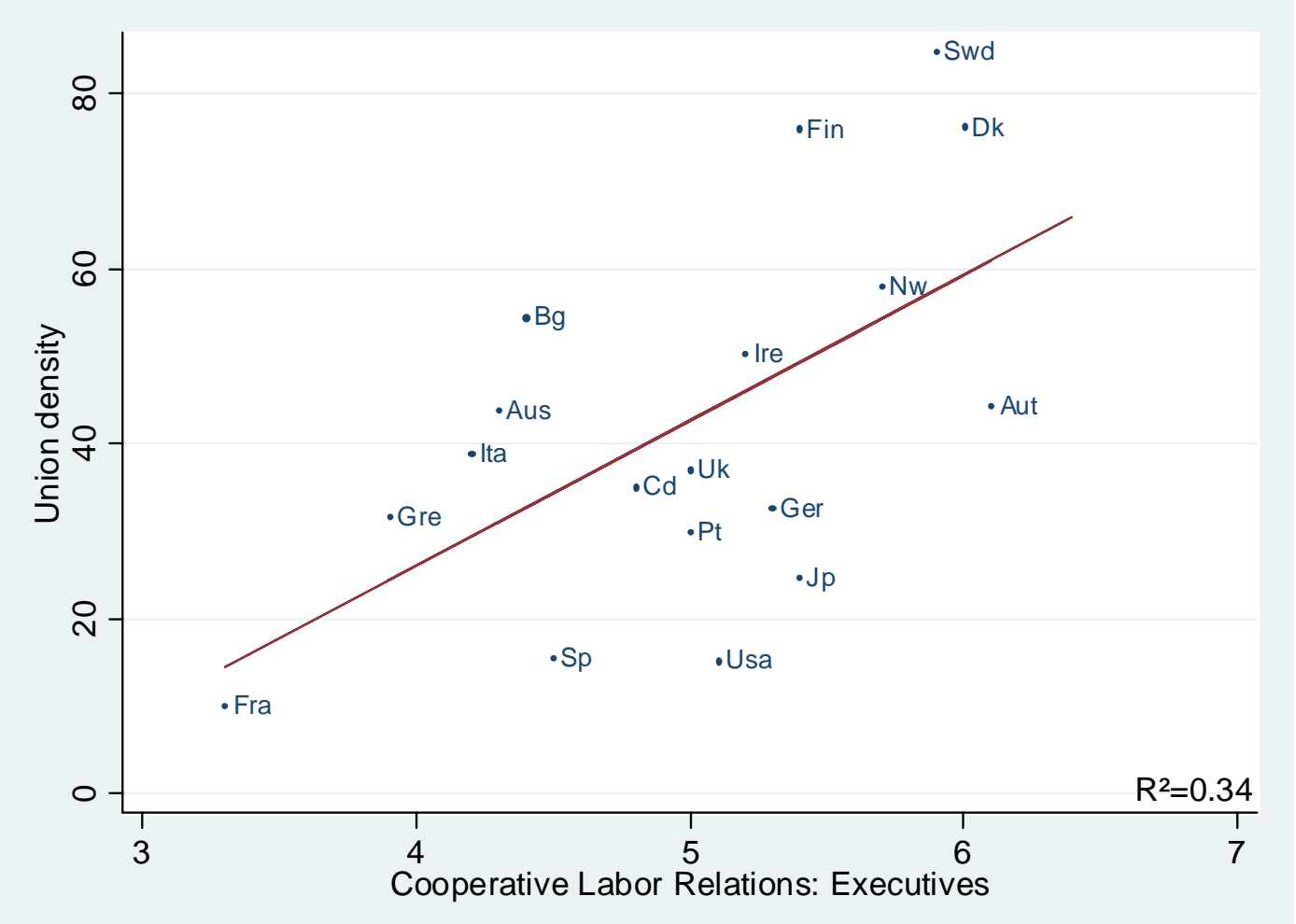

Figure 2: Correlation between Union density and Executives' beliefs in Cooperative labor relations. Source: OECD and GRC 1999 database. 
dustrial relations, a distinction first proposed by Hirshman (1970) and confirmed by Figure 2 . By showing that more stringent minimum wages increase the probability that the economy will fall in a low trust/low unionization trap, our model predicts a negative causality from wage regulation to unionization and trust in labor markets.

To account for the reverse causality from weak cooperation and unionization rates to high minimum wage regulations, we close the model by letting the minimum wage be set by an elected government that maximizes social welfare each period. In countries where beliefs in cooperation are too low to sustain involvement in trade unions, there is a strong demand for active state interventions in minimum wage regulation, which in turn results in a higher minimum wage being set by the government in equilibrium.

This two-way negative relationship between state regulation of wages and cooperative beliefs can give rise to multiple equilibria, which in turn can explain the polarization of countries reported in Figure 2 and Figure 1. In particular, countries can be stuck in an equilibrium with high minimum wage and low union density. At the other extreme, in countries where beliefs about cooperation are optimistic enough to sustain unions and negotiations, the demand for the legal minimum wage is lower. The low stringency of the minimum wage legislation provides incentives to experiment social dialogue by joining unions and thereby learning to implement cooperative labor relations. This experimentation in turn makes it possible for such countries to converge towards an equilibrium with low minimum wage, cooperative labor relations and high union density.

Our learning model also predicts that the joint dynamics of the legal minimum wage and union density is history-dependent: countries starting with low social capital will typically converge toward equilibria with low union density and high minimum wage, whereas countries starting with high social capital will converge to high unionization and low minimum wage steady states. This representation of the building-up of social capital as resulting from experimentation in collective action can explain the high degree of persistence in cooperative values found by Putnam (1993) and confirmed by Guiso et al. (2007a). In particular, if initial beliefs about cooperation are too pessimistic, a country can be persistently trapped in a no-experimentation equilibrium characterized by strong state regulation of the minimum wage, low union rates and distrustful labor relations. This explanation is complementary to the one proposed by Tabellini (2007b) where parents rationally choose which values to transmit to their offspring, and this choice is in turn influenced by the quality of external enforcement of values. In Tabellini's framework, values evolve gradually over time and if the quality of external enforcement is chosen under majority rule, there is hysteresis in the dynamics of values: adverse initial conditions, with weak enforcement, may lead to an equilibrium path where external enforcement remains 
weak and individual values discourage cooperation. ${ }^{6}$

This paper has also some connections with the litterature stressing the co-evolution of policies and beliefs, along the lines of Piketty (1995), Alesina and Angeletos (2005) and Benabou and Tirole (2006). In Piketty (1995), multiple equilibria in beliefs and redistributive policies can originate from the heterogeneity in initial beliefs and the difficulty for indviduals to learn the true cost and benefits of redistribution. Benabou and Tirole (2006) suggest that agents can deliberately bias their own perception of the truth. In Alesina and Angeletos (2005), multiplicy originates in the preference for fair economic outcomes.

The contribution of our paper is to focus on the interplay betwen policy and social capital. We assess the interaction between the State and the Civil Society. Moreover we provide a new rationale for multipe equilibria in institutions and beliefs that do not rely on initial heterogenity. Countries starting with the same beliefs in cooperation can diverge, and some of them fall into a no-investment in social capital trap, depending on historical idiosyncracies.

The paper is organized as follows. In Section 2 we present our model of social experimentation and minimum wage policy and use it to identify a two-way negative relationship between the quality of labor relations and the extent of state regulation of wages. In Section 3 we present the data used to test the predictions of the model. Section 4 provides evidence on the twoway relationship between the quality of labor relations and the extent of state regulation of wages. Section 5 documents the negative correlation between minimum wage regulation and union density. Section 6 concludes.

\section{The model}

\subsection{Basic framework}

We consider an infinite horizon economy populated by a continuum of measure one of risk neutral individuals, each of whom lives for one period. There are two non storable goods in the economy: a numeraire good and labor. Each individual is endowed with one unit of labor. Individuals get utility from their consumption of the numeraire good and they differ in productive ability. In each period $t$, the proportion of individuals who produce less than $y, y \geq 0$, with one unit of labor, is defined by the cumulative distribution function $G(y)$. For simplicity, we shall take the $G$ distribution to be uniform on the interval $[0,1]$.

Individuals may decide to join a trade union. The utility of an individual paid wage $w_{t}$ in

\footnotetext{
${ }^{6}$ See also Bisin and Verdier (2000), Lindbeck and Nyberg (2006) and Guiso et al. (2007b) for alternative formulation of transmission of beliefs and norms from parents to children.
} 
period $t$, is just equal to $w_{t}$ if the individual is not unionized and to

$$
v_{t}=w_{t}-c
$$

if she is unionized, where $c \in(0,1)$ denotes the cost of unionization.

Workers face a monopsonistic representative firm. First, the firm makes take-it-or-leave-it offers to non unionized workers. Consequently, non unionized workers cannot get more than the minimum wage $\bar{w}_{t} \geq 0$ set by the government if their productivity $y$ is higher than the minimum wage, and they get no job offer from the firm otherwise (we implicitly assume that workers' productivity characteristics are publicly observable).

Unionization allows workers to negotiate and obtain a share of output provided labor relations are sufficiently "cooperative". We model the negotiation between the union and the firm as an ultimatum game: first, the union makes an investment in its relationship with the firm; then the firm either responds to that investment by paying unionized workers their full marginal productivity (in this case the quality of labor relation is high) or the firm does not reciprocate (in which case the quality of labor relation is low). Thus, the cooperative nature (or quality) of labor relations depends upon two factors. First, the investment by unions in social capital relation. ${ }^{7}$ Second, the firm responses to the union's investment. Note that our modeling of the negotiation between union and firm, departs from traditional bargaining models. It would be easy to add bargaining considerations to the framework, although we believe that this would not add much to our interpretation and understanding of the observed negative relationship between minimum wage regulations and trust.

The true cooperative nature of labor relations is not observable. Workers only observe the outcome of their bargaining with the firm. ${ }^{8}$ In every period, the bargaining can either be: (i) a success, in which case all type- $y$ unionized workers get a wage equal to their productivity $w_{t}(y)=y ;^{9}$ (ii) or a failure, in which case workers obtain the minimum wage $w_{t}(y)=\bar{w}_{t} \cdot{ }^{10}$

\footnotetext{
${ }^{7}$ In Appendix B we provide evidence to the effect that union investment matters for trust in labor relations. There, we measure the union's investment in cooperation in two ways, following Checchi and Lucifora (2002). First, by the degree of workplace presence of unions. Second, by the degree to which unions coordinate and centralize their decisions. Figure 12 reports the correlation between the indicator of workplace presence of unions and the perceived quality of labor relations measured by the Global Competitiveness Reports 1999 . Figure 13 reports the same correlation pattern between the quality of labor relations and the degree of coordination and centralization of negotiations between trade unions. In both cases, steady positive correlations show up, suggesting that the quality of labor cooperation is strongly associated with investment in cooperation by unions.

${ }^{8}$ For the sake of simplicity, it is assumed that workers are able to extract the same information about the outcome of negotiation independently of the number of employees whose wage is bargained over by the trade union. Alternatively, one could assume that workers observe the outcome of negotiation with a probability that increases with the number of employees whose wage is bargained over in the period. Our results are robust to introducing this additional feature to the model.

${ }^{9}$ The assumption that workers obtain the whole surplus if bargaining succeeds, is made for notational simplicity. Assuming that the worker get a share $\beta \in[0,1]$ of the surplus would lead to similar results.

${ }^{10}$ Note that the wages negotiated by the trade union depend upon workers' productivity, whereas the minimum
} 
In each period $t$, bargaining between workers and the firm succeeds with a probability that depends upon the quality of labor relations: ${ }^{11}$

$$
\begin{gathered}
\operatorname{Pr} \text { (bargaining succeeds })=\left\{\begin{array}{cl}
1-\varepsilon & \text { if quality of labor relations is high } \\
\varepsilon & \text { if quality of labor relations is low, }
\end{array}\right. \\
\operatorname{Pr} \text { (bargaining fails) }=\left\{\begin{array}{cl}
1-\varepsilon & \text { if quality of labor relation is low, } \\
\varepsilon & \text { if quality of labor relation is high }
\end{array}\right.
\end{gathered}
$$

where $\varepsilon<1 / 2$.

\section{Investment in cooperation and the dynamics of beliefs}

The union can invest to improve the quality of labor relations. We denote the union's specific investment by $i_{t}$. For simplicity, assume that $i_{t}$ can take only two values: zero or $I>0$. The investment is publicly observable. When $i_{t}=0$, the quality of labor relations is necessarily low. When $i_{t}=I$, the quality of labor relations is high with probability $q_{t}$, and it remains low with the complementary probability $1-q_{t}$.

Upon deciding whether or not to invest in the quality of labor relations, unionized workers do not know whether they live in a cooperative economy where the investment will indeed lead to high quality of labor relations or if they live in a non-cooperative economy where such investment is pointless. In other words, the investment decision can be seen as a costly experimentation to improve labor relations and discover the true cooperative nature of the economy.

Let $e \in\{C, N\}$ denote the type of the economy: $C$ if the economy is cooperative and $N$ if it is non cooperative. We let

$$
\operatorname{Pr}_{t=0}(e=C)=q_{0}
$$

denote workers' prior beliefs as to the cooperative nature of the economy at date zero.

A history $h_{t}(n, s)$ at the beginning of period $t$ consists in $n \leq t$ past negotiations (between date 0 and date $t-1$ ) over which unions have invested in cooperation, $s \leq n$ of which have been successful, and $n-s$ have been unsuccessful. The number $n$ of periods with negotiation and positive investment, may be smaller than $t$ for two reasons. First, the trade union does not necessarily invest in every period. Second, there is no negotiation in the periods where nobody is unionized.

wage is independent of productivity. Here we simply capture the idea that trade unions have a better information about workers' productivity than the government.

${ }^{11}$ That bargaining does not succeed with probability one if the quality of labor relation is high, reflects the fact that the quality of labor relation is not perfect. That it may succeed with positive probability $\varepsilon$ when the quality of labor relation is low, reflects the fact that workers may sometime overcome the non-cooperative nature of the employer and still manage to strike a good deal. 
From Bayes' rule, we have:

$$
q_{t}=\operatorname{Pr}\left[e=C \mid h_{t}(n, s)\right]=\frac{(1-\varepsilon)^{s} \varepsilon^{n-s} q_{0}}{(1-\varepsilon)^{s} \varepsilon^{n-s} q_{0}+(1-\varepsilon)^{n-s} \varepsilon^{s}\left(1-q_{0}\right)} .
$$

Finally, using the fact that $\operatorname{Pr}\left[e=C \mid h_{t}(n, s)\right]=1-\operatorname{Pr}\left[e=N \mid h_{t}(n, s)\right]$, we can compute the probability that bargaining succeeds in period $t$ when there have been $n$ previous periods with investment and negotiations, $s$ of which have been successful, namely:

$$
p\left(q_{t}, i_{t}\right)=\left\{\begin{array}{cc}
\varepsilon+(1-2 \varepsilon) q_{t} & \text { if } i_{t}=I \\
\varepsilon & \text { if } i_{t}=0 .
\end{array}\right.
$$

In this framework, by unionizing and by investing in the quality of labor relations, workers manage both to obtain wage increases and also to generate information about the possibility to increase the quality of labor relations. In periods in which the trade union invests and some workers are unionized, the outcome of the negotiation reveals information on the type of economy. This in turn enables workers of the future generation to update their beliefs. When there is no investment or when nobody is unionized in period $t$, workers of generation $t+1$ cannot update their beliefs.

Bayes' rule immediately implies a positive correlation between beliefs in successive periods as stated by:

Lemma 1: In periods where the trade union invests $I$, the belief $p\left(q_{t}, I\right)$ that bargaining succeeds in period $t$ is non-decreasing with $p\left(q_{t-1}, i_{t-1}\right)$.

Proof: From the definition (19) of beliefs we know that $p\left(q_{t}, I\right)$ increases with $q_{t}=\operatorname{Pr}\left[e=C \mid h_{t}(n, s)\right]$. Let

$$
a=\operatorname{Pr}\left[e=C \mid h_{t}(n, s)\right] ; b=\operatorname{Pr}\left[e=C \mid h_{t-1}\left(n^{\prime}, s^{\prime}\right)\right]
$$

where $n^{\prime}=n$, or $n^{\prime}=n-1$, and $s^{\prime}=s$ or $s^{\prime}=s-1$. We have:

$$
\begin{aligned}
& 1 / a=1+\left(\frac{1-q_{0}}{q_{0}}\right)\left(\frac{1-\varepsilon}{\varepsilon}\right)^{n-2 s} ; \\
& 1 / b=1+\left(\frac{1-q_{0}}{q_{0}}\right)\left(\frac{1-\varepsilon}{\varepsilon}\right)^{n^{\prime}-2 s^{\prime}} .
\end{aligned}
$$

Thus

$$
1 / a=(1 / b)\left(\frac{1-\varepsilon}{\varepsilon}\right)^{n-n^{\prime}-2\left(s-s^{\prime}\right)}+1-\left(\frac{1-\varepsilon}{\varepsilon}\right)^{n-n^{\prime}-2\left(s-s^{\prime}\right)} .
$$

In particular $(1 / a)$ and $(1 / b)$ are positively correlated, and thus so are $a$ and $b$. QED.

\section{Timing}


At the beginning of period $t=0$, nature determines once for all the type of economy $e \in$ $\{C, N\}$ which is not observable. Then, in each period $t \geq 0$, the sequence of decisions can be described as follows: ${ }^{12}$

1. The trade union decides whether or not to invest in the quality of labor relations.

2. Individuals vote to elect a government that sets a minimum wage $\bar{w}_{t} \geq 0$.

3. Workers decide whether or not to join the trade union.

4. Wages are set by employers for non unionized workers and by wage negotiation for unionized workers.

We first analyze the outcome of the wage negotiation and the decision to invest in labor relations and to unionize when the minimum wage is exogenous. This first step will allow us to shed light on the relations between the minimum wage, unionization and investment behaviors and beliefs. Then, we endogeneize the minimum wage by making it a choice variable by the elected government.

\subsection{The effect of minimum wage on the dynamics of cooperation and beliefs}

Unionization behavior and investment in labor relations are influenced by beliefs about the efficiency of the investment and by the minimum wage. Beliefs are themselves influenced by past unionization and investment experience. In this section, we first analyze how the minimum wage influences unionization and investment behavior within each period $t$, taking beliefs are given. Then, we proceed to analyze the impact of the minimum wage on the dynamics of beliefs and unionization.

\subsubsection{Short run equilibrium}

Here we analyze unionization and investment in labor relations within any period $t$, with given belief $q_{t}=\operatorname{Pr}\left[e=C \mid h_{t}(n, s)\right]$ and given minimum wage $\bar{w}_{t}$. All workers whose productivity is lower than the minimum wage $\bar{w}_{t}$ are unemployed. Non unionized workers with productivity $y \geq \bar{w}_{t}$ obtain the minimum wage $\bar{w}_{t} \geq 0$. Unionized workers with productivity $y \geq \bar{w}_{t}$ expect to get the wage $w_{t}(y)=y$ with probability $p\left(q_{t}, i_{t}\right)$ and the minimum wage with probability $1-p\left(q_{t}, i_{t}\right)$.

\footnotetext{
${ }^{12}$ Here it is assumed that the trade union invests before the government sets the wage. This assumption has been chosen because investment in the quality of labor relations can be interpreted as a commitment device. However, it should be noticed that our main result of multiplicity of steady states, some with investment, others without, also holds when the wage is set before investment and when investment and wage are chosen simultaneously.
} 


\section{Unionization decision}

Workers decide to join unions in period $t$ if and only if the utility derived from union membership, equal to $p\left(q_{t}, i_{t}\right) y+\left[1-p\left(q_{t}, i_{t}\right)\right] \bar{w}_{t}-c$, is larger than the utility obtained without union membership, equal to the minimum wage $\bar{w}_{t}{ }^{13}$ Therefore, all workers whose productivity lies above the threshold

$$
\hat{y}_{t}=\bar{w}_{t}+\frac{c}{p\left(q_{t}, i_{t}\right)}
$$

decide to become union member. The share of workers who decide to join a union in period $t$ is therefore equal to:

$$
\pi_{t}=1-G\left(\bar{w}_{t}+\frac{c}{p\left(q_{t}, i_{t}\right)}\right) .
$$

In particular the share of unionized workers decreases with the minimum wage, the reason simply being that the gains from unionization are lower when the minimum wage is higher. More pessimistic beliefs about the chance of success of bargaining also lead to lower union density.

\section{Investment/experimentation decision}

The trade union's objective is to maximize the sum of the rents of its members, equal to the difference between what they get when they are unionized and the minimum wage they get for sure when not unionized, namely:

$$
\int_{\bar{w}_{t}+\frac{c}{p\left(q_{t}, i_{t}\right)}}^{1}\left[p\left(q_{t}, i_{t}\right)\left(y-\bar{w}_{t}\right)-c\right] \mathrm{d} G(y) .
$$

Recall that if there is investment in the quality of labor relations (i.e. if $i_{t}=I$ ), the negotiation succeeds with probability $p\left(q_{t}, I\right)$ equal to $\varepsilon+(1-2 \varepsilon) q_{t}$, whereas the probability of success falls down to $p\left(q_{t}, 0\right)=\varepsilon$ in the absence of investment.

Let $\Delta\left(\bar{w}_{t}, q_{t}\right)$ denote the difference between the value of the rents when investment takes place and the value of the rents when there is no investment. ${ }^{14}$ There is investment in labor relations if and only if

$$
\Delta\left(\bar{w}_{t}, q_{t}\right)>I \text {. }
$$

\footnotetext{
${ }^{13}$ Note that the decision to join the trade union is motivated here by individual gains only and not by social custom as in the approach developed by Akerlof (1980), Booth (1985), Booth and Chatterji (1993), Corneo (1995), Naylor (1989) and Naylor and Crips (1993) and Naylor and Raaum (1993).

${ }^{14}$ Simple calculation shows that

$$
\Delta\left(\bar{w}_{t}, q_{t}\right)=\int_{\bar{w}_{t}+\frac{c}{q_{t}(1-2 \varepsilon)+\varepsilon}}^{1}\left\{\left[q_{t}(1-2 \varepsilon)+\varepsilon\right]\left(y-\bar{w}_{t}\right)-c\right\} \mathrm{d} G(y)-\int_{\bar{w}_{t}+\frac{c}{\varepsilon}}^{1}\left[\varepsilon\left(y-\bar{w}_{t}\right)-c\right] \mathrm{d} G(y)
$$
}


It is easily checked that $\Delta$ is increasing in $q_{t}$ and decreasing in the minimum wage $\bar{w}_{t}$. More precisely, we get

$$
\begin{aligned}
\frac{\partial \Delta\left(\bar{w}_{t}, q_{t}\right)}{\partial \bar{w}_{t}} & =-q_{t}\left(1-\bar{w}_{t}\right)(1-2 \varepsilon)<0, \\
\frac{\partial \Delta\left(\bar{w}_{t}, q_{t}\right)}{\partial q_{t}} & =(1-2 \varepsilon) \int_{\bar{w}_{t}+\frac{c}{q_{t}(1-2 \varepsilon)+\varepsilon}}^{1}\left(y-\bar{w}_{t}\right) \mathrm{d} G(y)>0 .
\end{aligned}
$$

Thus the trade union is more likely to invest when the minimum wage is lower and when workers are more optimistic about the returns of the investment. In particular investment will never occur if the investment cost $I$ is higher than the maximum expected gains which arise when the minimum wage is equal to zero and people are the most optimistic, i.e. when $q_{t}=1$. In order to avoid such situations we assume henceforth that

$$
\Delta(0,1)>I
$$

or equivalently $I<\frac{1}{2}\left(\frac{1-\varepsilon+c^{2}}{1-\varepsilon}\right)-\varepsilon$.

The minimum wage policy and the no experimentation trap

Investment and unionization decisions depend upon beliefs and the minimum wage. Workers unionize more when they are more optimistic about the chance of success of negotiation and when the minimum wage is lower. And the trade union invests more to improve labor relations when workers are more optimistic about the returns to the investment and when the minimum wage is lower.

Figure 3 describes the short-run equilibrium for investment and unionization given $\left(q_{t}, \bar{w}_{t}\right)$ (the details underlying Figure 3 are presented in the appendix). Three regions, corresponding to three different type of equilibria, show up:

i) when workers are optimistic and the minimum wage is low, then there is positive union density and positive investment;

ii) when the minimum wage is low and workers are pessimistic, there is no investment to improve labor relations, but there is positive union density, albeit lower than in the previous situation;

iii) when the minimum wage is high, there is no investment and union density is nil.

Figure 3 illustrates that a high minimum wage can prevent the trade union from investing in the quality of labor relations. This is more likely to occur when workers are more pessimistic about the potential payoff from such investment, i.e on the cooperative nature of the environment. 


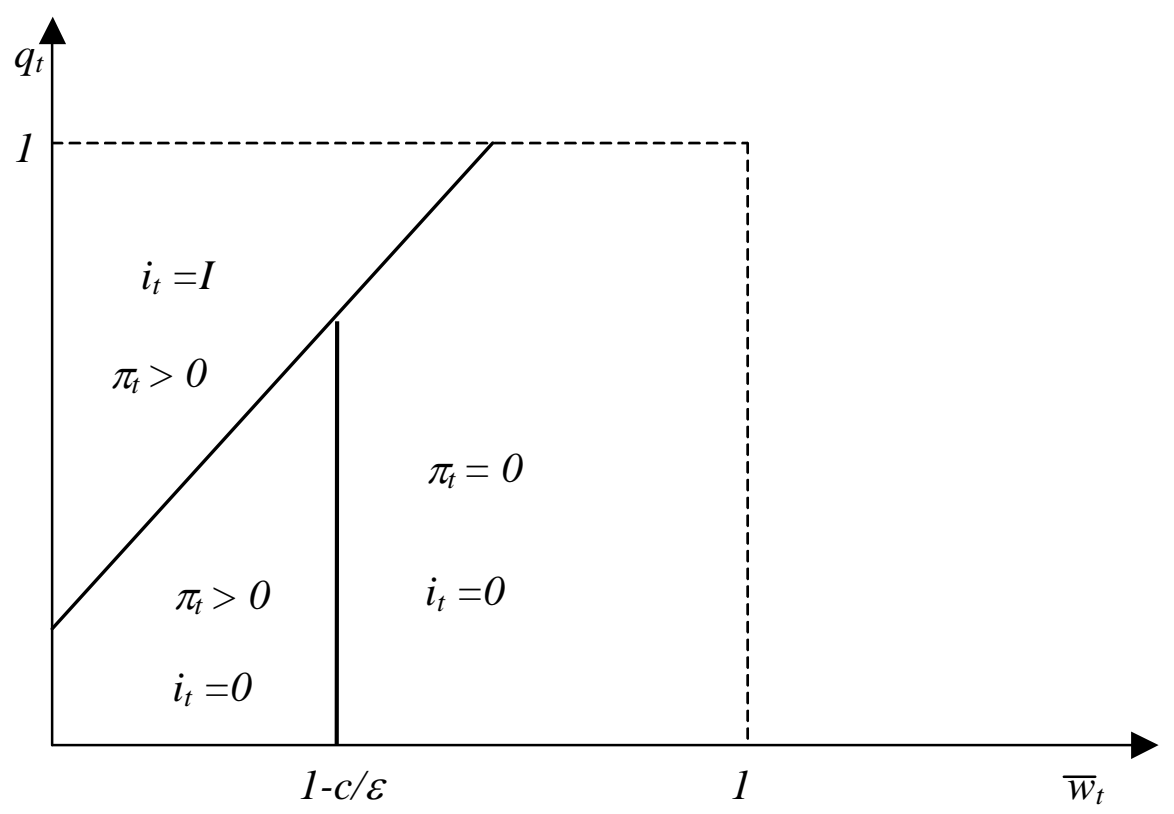

Figure 3: Experimentation and unionization in the $\left(q_{t}, \bar{w}_{t}\right)$ plane.

\subsubsection{The dynamics of beliefs, unionization and experimentation}

We now proceed to analyze the dynamics of beliefs, investment and unionization when the minimum wage is exogenously fixed at some level $\bar{w}$, for all periods $t \geq 0$. According to figure 3 , there are potentially three different possible steady states:

i) A steady state where $i=I$ and $\pi>0$,

ii) A steady state where $i=0$ and $\pi>0$,

iii) A steady state where $i=\pi=0$.

Suppose first that there is no investment in period $t=0$. In this case, the economy reaches its steady state immediately since beliefs are never revised thereafter. This case occurs if the initial value of the belief, $q_{0}$, is such that the net gain of investment is negative in period zero, i.e. if $\Delta\left(\bar{w}, q_{0}\right) \leq I$, or equivalently if

$$
q_{0}<\bar{q}=\{q \mid \Delta(\bar{w}, q)=I\}
$$

since $\Delta(\bar{w}, q)$ is increasing in $q$. As shown in figure 3, two possible steady states are possible in this situation, corresponding to cases $i$ ) and $i i$ ). If the minimum wage is sufficiently low, i.e. if $\bar{w}<1-\frac{c}{\varepsilon}$, the economy is stuck in a steady state where the share of unionized workers is positive, equal to $1-\frac{c}{\varepsilon}-\bar{w}$. If the minimum wage is above $1-\frac{c}{\varepsilon}$, the economy is stuck in a steady state with zero union density. 
Now suppose that

$$
q_{0}>\bar{q}
$$

and that the minimum wage is sufficiently low that experimentation occurs in period $t=0$. In this case, the dynamics of experimentation may lead the economy to converge towards a steady state with positive union density and investment. However, such optimistic beliefs in period zero are not sufficient to insure that the steady state with positive investment will indeed be reached.

More specifically, when $q_{0}>\bar{q}$, the economy converges toward such steady state with a positive probability, which will shown below to depend both upon the minimum wage $\bar{w}$ and upon $q_{0}$.

Note first that if negotiation succeeds in period zero, then we must have: $q_{1}=\operatorname{Pr}_{t=1}(e=C)>$ 0 and $p_{1}(1,1)>p_{0}$. This implies that the expected return from investment at date $1, \Delta\left(\bar{w}, q_{1}\right)$, is higher than in period zero. Thus

$$
q_{1}>q_{0} .
$$

The same increase in workers' optimism occurs between periods $t$ and $t+1$ occurs when negotiation succeeds in period $t$.

Overall, the dynamics of beliefs when there is investment, is fully described by:

$$
q_{t+1}=\left\{\begin{array}{lll}
q_{t} & \text { if } q_{t} \leq \bar{q} \\
\frac{(1-\varepsilon) q_{t}}{(1-\varepsilon) q_{t}+\varepsilon\left(1-q_{t}\right)}>q_{t} & \text { with probability } 1-\varepsilon & \text { if } q_{t}>\bar{q} \\
\frac{\varepsilon q_{t}}{\varepsilon q_{t}+(1-\varepsilon)\left(1-q_{t}\right)}<q_{t} & \text { with probability } \varepsilon & \text { if } q_{t}>\bar{q}
\end{array}\right.
$$

if the economy is type- $C$, and

$$
q_{t+1}=\left\{\begin{array}{lll}
q_{t} & \text { if } q_{t} \leq \bar{q} \\
\frac{(1-\varepsilon) q_{t}}{(1-\varepsilon) q_{t}+\varepsilon\left(1-q_{t}\right)}>q_{t} & \text { with probability } \varepsilon & \text { if } q_{t}>\bar{q} \\
\frac{\varepsilon q_{t}}{\varepsilon q_{t}+(1-\varepsilon)\left(1-q_{t}\right)}<q_{t} & \text { with probability } 1-\varepsilon & \text { if } q_{t}>\bar{q}
\end{array}\right.
$$

if the economy is type- $N$.

A first implication of the updating equation (10) is that as the experimentation history expands, the reference type ends up being learned with probability 1 . More formally, the continuous mapping theorem (see Acemoglu et al, 2007) implies that $s \rightarrow(1-\varepsilon) t$ as $t \rightarrow \infty$ when experimentation occurred in all periods $0,1, \ldots, t-1$, which in turn implies that

$$
\lim _{t \longrightarrow \infty} \operatorname{Pr}\left[e=C \mid h_{t}(t, s)\right]=\lim _{t \longrightarrow \infty} \frac{q_{0}}{q_{0}+\left(\frac{\varepsilon}{1-\varepsilon}\right)^{t(1-2 \varepsilon)}\left(1-q_{0}\right)}=1 .
$$

However, as we shall see below, experimentation may not occur in all periods even when the economy is cooperative $(e=C)$. And as a result the economy will not avoid falling into a no investment/ no experimentation trap with probability one. The continuous mapping theorem 
also yields that $\lim _{t \longrightarrow \infty} \operatorname{Pr}\left[e=C \mid h_{t}(t, s)\right]=0$ if $e=N$, which this time will imply that with probability one the economy falls into a no experimentation/no investment trap. From now on we shall concentrate on the case where the economy is truly cooperative (type- $C$ ).

A second implication of the updating equation (10), is that the probability of uninterrupted experimentation (and therefore of convergence toward full learning) increases with the value of the initial beliefs $q_{0}$. For example, if $q_{0}$ is larger than the threshold value $\bar{q}$ below which there is no investment, but close enough to $\bar{q}$, the probability that there is investment in period zero, but then no investment in subsequent periods, can be high. To see this, imagine that $q_{0}>\bar{q}$ but that negotiation fails in period zero (this occurs with probability $\varepsilon$ ). Then, equation (10) implies that $q_{1}<q_{0}$. If $q_{1}$ is smaller than $\bar{q}$, which will occur if $q_{0}$ is close enough to $\bar{q}$, investment is equal to zero in period one. In that case, the economy falls in a no-investment/no-experimentation trap in period 1, after one period of experimentation, and from period zero this case is perceived to occur with probability $\varepsilon$.

For higher values of $q_{0}$ it will take more than one failure to bring the economy to a noinvestment/no-experimentation trap. Such a scenario can occur after period 1 when there are successive failures for higher values of $q_{0}$. More precisely, we can show:

Proposition 1: If the economy is of the cooperative type $(e=C)$ and if $q_{0}>\bar{q}$, then the economy avoids the no-investment/ no-experimentation trap with probability $Q\left(q_{0}, \bar{w}\right)$ which is increasing in $q_{0}$ and decreasing in $\bar{w}$.

Proof: Let $T\left(q_{0}, \bar{q}\right)$ be defined by

$$
\varphi\left(T, q_{o}\right)=\bar{q},
$$

where:

$$
\varphi\left(T, q_{o}\right)=\frac{1}{1+\left(\frac{1-q_{0}}{q_{0}}\right)\left(\frac{1-\varepsilon}{\varepsilon}\right)^{T}} .
$$

Since $\varphi$ is decreasing in $T$ and increasing in $q_{0}$, then $T\left(q_{0}, \bar{q}\right)$ is increasing in $q_{0}$ and decreasing in $\bar{q}$.

Now the ex ante expected probability that $q_{t}$ will eventually fall below $\bar{q}$, which in turn will lead to a no-investment/no-experimentation trap, is equal to ${ }^{15}$ :

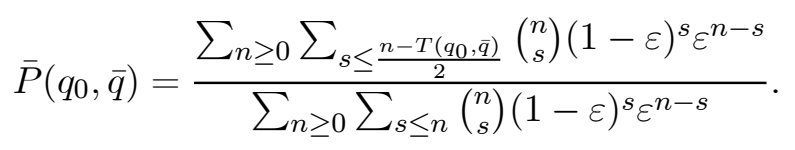

\footnotetext{
${ }^{15}$ Here we use the fact that
}

$$
q_{t}=\operatorname{Pr}\left[e=C \mid h_{t}(n, s)\right]=\frac{1}{1+\left(\frac{1-q_{0}}{q_{0}}\right)\left(\frac{1-\varepsilon}{\varepsilon}\right)^{n-2 s}} .
$$


In particular it is easy to see that $\bar{P}\left(q_{0}, \bar{q}\right)$ is decreasing in $T$, and therefore decreasing in $q_{0}$ and increasing in $\bar{q}$, and therefore

$$
Q\left(q_{0}, \bar{w}\right)=1-\bar{P}\left(q_{0}, \bar{q}\right)
$$

is increasing in $q_{0}$ and decreasing in $\bar{q}$ and therefore in the minimum wage $\bar{w}$. QED.

Thus, when the economy is truly cooperative, the economy is more likely to converge toward a steady state equilibrium with positive investment and union density if initial beliefs are sufficiently optimistic and the minimum wage is sufficiently low. Moreover, we can state that:

Result 1: In steady state, aggregate welfare of workers is higher in the equilibrium with positive investment in the quality of labor relations than in the equilibrium without investment.

\section{Proof:}

Aggregate welfare of workers in period $t$ is equal to the sum of wages minus the unionization costs and the investment costs in the quality of labor relations:

$$
W_{t}=\left[G\left(\bar{w}+\frac{c}{p\left(q_{t}, i_{t}\right)}\right)-G(\bar{w})\right] \bar{w}+\int_{\bar{w}+\frac{c}{p\left(q_{t}, i_{t}\right)}}^{1}\left[p\left(q_{t}, i_{t}\right) y+\left[1-p\left(q_{t}, i_{t}\right)\right] \bar{w}-c\right] \mathrm{d} G(y)-i_{t} .
$$

When $\bar{w}+\frac{c}{p\left(q_{t}, i_{t}\right)}$ is greater than 1 , then aggregate welfare is equal to:

$$
W_{t}=[1-G(\bar{w})] \bar{w}-i_{t} .
$$

A steady state equilibrium with positive investment in the quality of labor relations can exist only if the economy is truly cooperative and if $\bar{w}+\frac{c}{1-\varepsilon}<1$. Assuming that these two conditions are fulfilled, the probability $p\left(q_{t}, i_{t}\right)$ that bargaining succeeds at date $t$, is equal to $1-\varepsilon$ if there is investment in the quality of labor relations. Then, steady state welfare is

$$
W^{I}=\left[G\left(\bar{w}+\frac{c}{1-\varepsilon}\right)-G(\bar{w})\right] \bar{w}+\int_{\bar{w}+\frac{c}{1-\varepsilon}}^{1}[(1-\varepsilon) y+\varepsilon \bar{w}-c] \mathrm{d} G(y)-I .
$$

If there is no investment, then $p\left(q_{t}, i_{t}\right)$ is equal to $\varepsilon$ and steady state welfare amounts to

$$
W^{0}=\left\{\begin{array}{ll}
{\left[G\left(\bar{w}+\frac{c}{\varepsilon}\right)-G(\bar{w})\right] \bar{w}+\int_{\bar{w}+\frac{c}{\varepsilon}}^{1}[\varepsilon y+(1-\varepsilon) \bar{w}-c] \mathrm{d} G(y)} & \text { when } \bar{w}+\frac{c}{\varepsilon}<1 \\
{\left[G\left(\bar{w}+\frac{c}{\varepsilon}\right)-G(\bar{w})\right] \bar{w}} & \text { otherwise. }
\end{array} .\right.
$$

Using the two last equations and the definition of $\Delta(\bar{w}, q)$ given in footnote 14 it can easily be checked that $W^{I}>W^{0}$ since $\Delta(\bar{w}, 1)>I$. QED. 


\subsection{Optimal minimum wage and the multiplicity of steady-state social regimes}

In this section we analyze the reverse causality from current beliefs about cooperation to the minimum wage optimally chosen by a utilitarian government. We begin to define the optimal minimum wage set by the government in every period. Then, we proceed to analyze the shortrun equilibrium, when the belief about the efficiency of the investment in labor relations is taken as given. Finally, we study the dynamics of beliefs and investment and we show that the model generates multiple (long-term) social regimes.

\subsubsection{The ex-ante social welfare function and the optimal minimum wage}

It is assumed that the government, contrary to the trade union, does not observe the productivity of each individual. This assumption is meant to capture in a simple way the fact that trade unions gather information, thanks to the bargaining process, that is not available to the government. The cost of unionization, $c$, and/or the cost of investment in labor relations, $I$, can be interpreted as the cost of information obtained by the trade union.

Since the government does not observe productivity, the minimum wage can only be the lowest bound of the wage distribution. The election process is represented by a probabilistic voting model which implies, under some assumptions assumed to be fulfilled, that the elected government maximizes the sum of the utilities of the workers. ${ }^{16}$

We assume that the government chooses the minimum wage after the union has chosen its investment $i_{t}$. As shown previously, the trade union's investment choice satisfies:

$$
i_{t}=\left\{\begin{array}{ll}
I & \text { if } \Delta\left(\bar{w}_{t}, q_{t}\right)>I \\
0 & \text { if } \Delta\left(\bar{w}_{t}, q_{t}\right) \leq I .
\end{array},\right.
$$

where $\bar{w}_{t}$ is the minimum wage the union anticipates to be set by the government in period $t$.

Given $q_{t}$ and $i_{t}$, the government chooses the minimum wage $\bar{w}_{t}=\bar{w}\left(q_{t}, i_{t}\right) \geq 0$ that maximizes the social welfare function equal to the sum of the gains of the workers minus the investment costs:

$$
W_{t}=\left[G\left(\bar{w}_{t}+\frac{c}{p\left(q_{t}, i_{t}\right)}\right)-G\left(\bar{w}_{t}\right)\right] \bar{w}_{t}+\int_{\bar{w}_{t}+\frac{c}{p\left(q_{t}, i_{t}\right)}}^{1}\left[p\left(q_{t}, i_{t}\right) y+\left[1-p\left(q_{t}, i_{t}\right)\right] \bar{w}_{t}-c\right] \mathrm{d} G(y),
$$

where $p\left(q_{t}, i_{t}\right)$ is given by

$$
p\left(q_{t}, i_{t}\right)=\left\{\begin{array}{cc}
\varepsilon+(1-2 \varepsilon) q_{t} & \text { if } i_{t}=I \\
\varepsilon & \text { if } i_{t}=0
\end{array}\right.
$$

\footnotetext{
${ }^{16}$ This outcome can be derived from the simple case in which individuals are heterogeneous with respect to ideological biases towards the candidates. Then, following Persson and Tabellini (2000) it turns out that the outcome of the elections maximizes the utilitarian criterion if the ideological bias is represented by an additive term in the utility function and is distributed with a uniform distribution independent of the distribution of productivities.
} 
When $\bar{w}_{t}+\frac{c}{p\left(q_{t}, i_{t}\right)}$ is greater than 1 , then social welfare is equal to:

$$
W_{t}=\left[1-G\left(\bar{w}_{t}\right)\right] \bar{w}_{t}-i_{t}
$$

Maximizing welfare over the choice of minimum wage $\bar{w}_{t}$, we can establish the following

Proposition 2: The optimal minimum wage $\bar{w}\left(q_{t}, i_{t}\right)$ at date $t$ is equal to:

$$
\bar{w}\left(q_{t}, i_{t}\right)= \begin{cases}\frac{c+1-p\left(q_{t}, i_{t}\right)}{2-p\left(q_{t}, i_{t}\right)} & \text { if } p\left(q_{t}, i_{t}\right) \geq 2 c \\ 1 / 2 & \text { if } p\left(q_{t}, i_{t}\right) \leq 2 c .\end{cases}
$$

Proof: Consider first the case when the welfare maximization program has an interior solution $\bar{w}_{t}>0$ such that

$$
\bar{w}_{t}+\frac{c}{p\left(q_{t}, i_{t}\right)}<1 .
$$

Then the optimal minimum wage satisfies the first order condition:

$$
\frac{\partial W_{t}}{\partial \bar{w}_{t}}=0, \text { or equivalently: } \bar{w}_{t}=\frac{c+1-p\left(q_{t}, i_{t}\right)}{2-p\left(q_{t}, i_{t}\right)} .
$$

The solution $\bar{w}_{t}$ is truly interior if

$$
\frac{c+1-p\left(q_{t}, i_{t}\right)}{2-p\left(q_{t}, i_{t}\right)}+\frac{c}{p\left(q_{t}, i_{t}\right)}<1
$$

or equivalently

$$
p\left(q_{t}, i_{t}\right)>2 c
$$

Now suppose that

$$
p\left(q_{t}, i_{t}\right) \leq 2 c
$$

then the optimal minimum wage $\bar{w}_{t}$ maximizes

$$
W_{t}=\left[1-G\left(\bar{w}_{t}\right)\right] \bar{w}_{t}
$$

Note that in this case

$$
\frac{\partial W_{t}}{\partial \bar{w}_{t}}=1-2 \bar{w}_{t}
$$

which is positive if $\bar{w}_{t}<1 / 2$ and negative otherwise. Thus in this case the optimal minimum wage is simply

$$
\bar{w}_{t}=\frac{1}{2}
$$

which establishes the proposition. QED. 


\subsubsection{Short run equilibrium, for given current beliefs about cooperation}

We now proceed by backward induction. Consider first the government's choice of minimum wage for given beliefs and union investment. Proposition 2 gives us the answer, namely:

If $i_{t}=0$, then the probability that bargaining succeeds is $p\left(q_{t}, 0\right)=\varepsilon$ and the government sets

$$
\bar{w}\left(q_{t}, 0\right)= \begin{cases}\frac{c+1-\varepsilon}{2-\varepsilon} & \text { if } \varepsilon \geq 2 c \\ 1 / 2 & \text { if } \varepsilon \leq 2 c .\end{cases}
$$

If $i_{t}=I$, the government will choose

$$
\bar{w}\left(q_{t}, I\right)= \begin{cases}\frac{c+1-\left[\varepsilon+(1-2 \varepsilon) q_{t}\right]}{2-\left[\varepsilon+(1-2 \varepsilon) q_{t}\right]} & \text { if } \varepsilon+(1-2 \varepsilon) q_{t} \geq 2 c \\ 1 / 2 & \text { if } \varepsilon+(1-2 \varepsilon) q_{t} \leq 2 c .\end{cases}
$$

which is decreasing in $q_{t}$ since $c<1$.

Now, moving back one step, the union will choose to invest, i.e $i_{t}=I$, whenever

$$
D\left(q_{t}\right)>I
$$

where

$$
\begin{aligned}
D(q)= & \int_{\bar{w}(q, I)+\frac{c}{q(1-2 \varepsilon)+\varepsilon}}^{1}\{[q(1-2 \varepsilon)+\varepsilon][y-\bar{w}(q, I)]-c\} \mathrm{d} G(y) \\
& -\int_{\bar{w}(q, 0)+\frac{c}{\varepsilon}}^{1}\{\varepsilon[y-\bar{w}(q, 0)]-c\} \mathrm{d} G(y) .
\end{aligned}
$$

Using the fact that $D(q)$ is increasing in $q$, the above inequality defines a lower bound

$$
\tilde{q}=\{q \mid D(q)=I\}
$$

on beliefs, ${ }^{17}$ below which the union does not invest and therefore does not experiment. Obviously, an equilibrium with positive investment cannot exist if the investment cost is higher than the expected gains from investment when people are most optimistic, i.e. when $q_{t}=1$. To avoid this possibility, we henceforth assume that

$$
D(1)>I \text {. }
$$

Then, either $q_{t}<\tilde{q}$, in which case the union does not invest and therefore the government sets minimum wage $\bar{w}_{t}=\min \left\{1 / 2, \frac{c+1-\varepsilon}{2-\varepsilon}\right\}$, or $q_{t}>\tilde{q}$ in which case the union invests, the government sets

$$
\bar{w}_{t}=\frac{c+1-\left[\varepsilon+(1-2 \varepsilon) q_{t}\right]}{2-\left[\varepsilon+(1-2 \varepsilon) q_{t}\right]}<1 / 2,
$$

and the union experiments at date $t$. Since the minimum wage is lower in the second case, union density is higher in that case.

\footnotetext{
${ }^{17}$ It can be checked that $\tilde{q}$ is larger than the threshold value of $q$ below which the wage $\bar{w}\left(q_{t}, I\right)=1 / 2$. This is because nobody is unionized if the wage is equal to $1 / 2$ and it is then never worth investing in the quality of labor relations.
} 


\subsubsection{Comparative static results}

Using Proposition 2 and plugging the equilibrium value of the minimum wage back into the expressions for welfare, employment and output, we can establish interesting comparative static results on how these three measures of aggregate performance vary with workers' belief on the type of the economy.

Result 2: Employment and aggregate output are non-decreasing with the previous period's belief in the cooperative nature of the economy.

Proof: Note that aggregate employment is simply given by

$$
E_{t}= \begin{cases}1-G\left(\bar{w}_{t}\right)=\frac{1-c}{2-p\left(q_{t}, i_{t}\right)} & \text { if } p\left(q_{t}, i_{t}\right) \geq 2 c \\ \frac{1}{2} & \text { otherwise. }\end{cases}
$$

Thus $E_{t}$ is non-decreasing in $p\left(q_{t}, i_{t}\right)$ and thus in $p\left(q_{t-1}, i_{t-1}\right)$ according to Lemma 1 and to Corollary 1. Similarly, aggregate output

$$
Y_{t}=\int_{\bar{w}_{t}}^{1} y \mathrm{~d} G(y)
$$

is non-decreasing in $p\left(q_{t-1}, i_{t-1}\right)$ since $\bar{w}_{t}$ is non-increasing in $p\left(q_{t-1}, i_{t-1}\right)$. QED.

When many workers were unionized in the previous generation and when the trade union has just invested to improve the quality of labor relations, the government can set a low minimum wage because current expected gains of unionization are high. This situation, which is favorable to employment and output, is also good for aggregate welfare which is equal to total wages net of total unionization and investment costs if the true nature of the economy is cooperative:

Result 3: When the economy is type-C, aggregate workers' welfare is non-decreasing with the previous generation's belief.

Proof: Past belief has no impact on current welfare if $q_{t}$ is such that there is no investment in the current period, i.e. if $q_{t} \leq \tilde{q}$. Let us now suppose that $q_{t}>\tilde{q}$ and that there is an equilibrium with positive investment in period $t$. Then, using the envelop theorem the derivative of $W_{t}$ (defined equation (13)) at the optimal value of $\bar{w}_{t}$ reads

$$
\frac{\mathrm{d} W_{t}}{\mathrm{~d} p\left(q_{t}, i_{t}\right)}= \begin{cases}\int_{\bar{w}_{t}+\frac{c}{p\left(q_{t}, i_{t}\right)}}^{1}\left(y-\bar{w}_{t}\right) \mathrm{d} G(y)>0 & \text { if } p\left(q_{t}, i_{t}\right) \geq 2 c \\ 0 & \text { otherwise. }\end{cases}
$$

Since from Lemma $1 p\left(q_{t}, i_{t}\right)$ increases with $p\left(q_{t-1}, i_{t-1}\right)$ when the trade union invests, $W_{t}$ also increases with $p\left(q_{t-1}, i_{t-1}\right)$ if $p\left(q_{t}, i_{t}\right) \geq 2 c$. QED.

Thus, when the true nature of the economy is cooperative, more optimistic past beliefs about the cooperative nature of the economy and the efficiency of investment, favor current involvement in collective action, and leads to higher social welfare because the action of trade unions is more efficient than the minimum wage to fight against the monopsony power of employers. 


\subsubsection{The dynamics of union density, minimum wage and investment in coopera- tion}

This section analyzes the joint dynamics of union density, minimum wages and investment in the quality of labor relations. We are particularly interested in the existence of multiplicity of steady-state equilibria: equilibria with positive investment in the quality of labor relations, low minimum wage and high unionization (a "Scandinavian" equilibrium) and equilibria without investment in the quality of labor relation, and with low unionization and high minimum wage ("French" equilibrium).

\section{"French" equilibrium}

When initial beliefs about the nature of the economy, $q_{0}=\operatorname{Pr}_{t=0}(e=C)$, are pessimistic, the economy can be stuck in a situation with zero investment. This occurs for sure if $q_{0} \leq \tilde{q}$. This situation persists over time since the absence of experimentation in period $t=0$ prevents the updating of beliefs in period 1 , and then in the subsequent periods $2, . ., \infty$. The minimum wage remains high, equal to

$$
\bar{w}=\min \left\{1 / 2, \frac{c+1-\varepsilon}{2-\varepsilon}\right\}
$$

and union density is equal to ${ }^{18}$

$$
\pi=\max \left\{0, \frac{\varepsilon-2 c}{\varepsilon(2-\varepsilon)}\right\}
$$

\section{"Scandinavian" equilibria}

When initial beliefs are sufficiently optimistic, i.e. when $q_{0}>\tilde{q}$, investment in period zero is positive. Then, social experimentation takes place. From our analysis in the previous subsection, we know that with ex-ante probability

$$
\bar{P}\left(q_{0}, \tilde{q}\right)=\frac{\sum_{n \geq 0} \sum_{s \leq \frac{n-T\left(q_{0}, \tilde{q}\right)}{2}}\left(\begin{array}{l}
n \\
s
\end{array}\right)(1-\varepsilon)^{s} \varepsilon^{n-s}}{\sum_{n \geq 0} \sum_{s \leq n}\left(\begin{array}{l}
n \\
s
\end{array}\right)(1-\varepsilon)^{s} \varepsilon^{n-s}},
$$

the economy will end up in a "French" trap, but with probability $\left[1-\bar{P}\left(q_{0}, \tilde{q}\right)\right]$ it will converge toward the "Scandinavian" steady state.

If the economy reaches the "Scandinavian" steady state, the economy had to be of a cooperative type (otherwise, the economy could not have converged toward this steady state by the

\footnotetext{
${ }^{18}$ By using the value of $\bar{w}_{t}$ defined in equation (15) into equation (4), we see that the unionization ragte at date $t$ in equilibrium is given by:

$$
\pi_{t}= \begin{cases}\frac{p\left(q_{t}, i_{t}\right)-2 c}{p\left(q_{t}, i_{t}\right)\left[2-p\left(q_{t}, i_{t}\right)\right]} & \text { if } p\left(q_{t}, i_{t}\right) \geq 2 c \\ 0 & \text { if } p\left(q_{t}, i_{t}\right) \leq 2 c\end{cases}
$$

In particular we see that:

$$
\partial \pi_{t} / \partial p_{t} \geq 0
$$

In other words, the more optimistic workers are about the quality of labor relations at date $t$, the more they unionize at that date.
} 
Continuous Mapping Theorem). The probability of success of negotiation is then equal to $1-\varepsilon$. The minimum wage and the trade union density are consequently given by

$$
\bar{w}^{*}=\frac{c+\varepsilon}{1+\varepsilon}<\frac{1}{2}, \pi^{*}=\frac{1-\varepsilon-2 c}{(1-\varepsilon)^{2}}>\pi \geq 0 .
$$

Welfare comparison

Consider a type- $C$ economy so that the steady state with positive investment can be reached when the initial beliefs satisfy $q_{0}>\tilde{q}$. Then, we know from Result 2 that aggregate welfare is increasing with $p\left(q_{t}, i_{t}\right)$. Since $p\left(q_{t}, i_{t}\right)$ is higher in the equilibrium with positive investment than in the equilibrium with zero investment, aggregate welfare is higher in the "Scandinavian" steady state equilibrium than in a "French" one.

The following proposition summarizes the above discussion:

Proposition 3: Assume a type-C economy. Then, there exists a steady state equilibrium with positive investment in the quality of labor relations, high unionization rate and low minimum wage. There also exist steady state equilibria with zero investment, low union density and high minimum wage. In the steady state with positive investment, welfare is higher than in the steady-state without investment.

If initial beliefs $q_{0}$ that the environment is cooperative are lower than $\tilde{q}$, the economy is stuck in a bad equilibrium with higher minimum wage $\bar{w}_{t}=\min \left\{1 / 2, \frac{c+1-\varepsilon}{2-\varepsilon}\right\}$, lower unionization rate, and no investment in the quality of labor relations.

If $q_{0}>\tilde{q}$, the economy converges towards the equilibrium with positive investment in the quality of labor relations, lower minimum wage $\bar{w}^{*}=\frac{c+\varepsilon}{1+\varepsilon}$, higher unionization rate, with probability $1-\bar{P}\left(q_{0}, \tilde{q}\right)$ that increases with $q_{0}$.

It is worth stressing that the dynamics of investment in cooperation, of unionization and of the minimum wage, are all driven by the updating of workers' beliefs. A high current minimum wage policy favors convergence towards the "low" equilibrium with no unionization and investment, as it deters experimentation and thereby leads to future minimum wage increases.

\section{Data and measurement}

\subsection{Measuring the state regulation of minimum wages}

To measure the stringency of state regulation of minimum wages we construct a composite index. A first component of this index is the stringency of the minimum wage legislation, including the 
existence of legal minimum wages and the extent of potential derogations. A second component is the level of the minimum wage. Data are borrowed from the International Labor Organization (ILO) and from the OECD database. The ILO database provides detailed description of the different legal procedures to set minimum wages. The OECD database provides information concerning the level of real minimum wages and the ratio of minimum wages relatively to average wages and median wages. The indicators are briefly described below, the full description being reported in Appendix C. The overall regulation index is simply the product of these two components.

\section{Minimum wage legislation}

We start by looking at the stringency of minimum wage legislations. This is measured by two main indicators: $i^{\circ}$ ) minwage_legal measures the existence of a legal statutory minimum wage, and if not, the degree of coverage of the minimum wage set by collective bargaining; $2^{\circ}$ ) minwage_dispersion measures the degree of dispersion in minimum wages across ages, qualifications, regions, sectors or occupations. We scale each of these two indicators between zero and one, a higher value indicating more stringent law enforcement.

Figure 4 shows the first indicator, minwage_legal, which captures the existence of a legal statutory minimum wage and the extent to which minimum wages negotiated in collective bargaining are extended to all workers. The indicator minwage_legal equal to 1 if a statutory minimum wage exists, 0.5 if instead the wage floor is directly bargained over by unions and then extended, and 0 otherwise. We report the average value of this indicator for the period 1980-2003. A high degree of cross-country variation shows up along this dimension. A first group of countries, namely Scandinavian countries, do not have any legal minimum wage, and no legal automatic extension of the negotiated wage floors. Wage floors are determined as part of the collective agreements between unions, and then they apply to workers covered by these collective agreements only. A similar group of countries, made up of Austria, Germany and Italy, do not have any legal statutory minimum wages. But legal dispositions stipulate to what extent the negotiated wage floors should be extended to all other workers. Lastly, a legal statutory minimum wage is implemented by most Mediterranean and Anglo-Saxon countries. In the United States, this tradition dates back at least to the 1938 Fair Act while it is more recent in United Kingdom which established a legal minimum wage in 1999.

Figure 5 shows the indicator minwage_dispersion which measures the extent of dispersion and derogations in minimum wage setting. Minimum wage can differ by ages, qualifications, regions, sectors or occupations. A more constraining minimum wage legislation is one that leaves little room for derogations and dispersion. We measure this characteristic by constructing two sub-indexes for age dispersion and other kind of derogations. The sub-indexes are ranked 
between 0 and 1, a higher score indicating that the country provides little derogation. The subindex of dispersion across ages is constructed as follows. The score is equal to 1 if there is no provision at all for sub-minimum wages. It is equal to 0.5 if derogations are restricted to workers younger than 18 years old or if the derogation is less than half the official minimum wage. And it takes on the value 0 if the derogations can be extended to people older than 18 years or/and if the sub-minimum wages are lower than half the standard wage floor. The sub-index for other derogations equal 0 if the minimum wage is allowed to differ along at least the three dimensions of regions, sectors and occupations, 0.33 if there are two types of distinctions, 0.67 for one type of distinction, and 1 if no dispersion at all is allowed. The indicator minwage_dispersion is the average of these two sub-indexes.

Figure 5 shows a great deal of cross-country heterogeneity in the minwage_dispersion indicator over the period 1980-2003. Countries like France leaves no scope for derogations based on age, occupation, or industry. Other countries allow for subminimum wages. Thus, special wage floors extend up to age 24 in Sweden and to age 22 years in the Netherlands. The Netherlands accepts a reduction up to 40 percent of standard minimum wage at 17 years old. Nordic countries let unions negotiate the wage floor at the industry level, without any automatic extension to other parts of the economy.

Henceforth, we measure the stringency of the overall minimum wage legislation using the composite indicator minwage_legislation, obtained by multiplying the indicator of legal determination of the minimum wage, minwage_legal, by the indicator of potential dispersion, minwage_dispersion.

\section{Minimum wage levels}

We measure the minimum wage level by the index minwage_level defined as the ratio of the minimum wage over the median wage in the economy. Minimum wage levels are provided by the OECD database for all years since the mid-1970s. The OECD only reports countries which have a legal statutory minimum wage. We thus complete these data by using Neumark and Wascher (2004)'s indicators for other countries. These data cover two time periods, the late 1970s and the 2000s. The exact definition of the minimum wage variables used to calculate the real value of national minimum wages, is reported in the Appendix. As mentioned above, minimum wage levels display some degree of dispersion within most countries. The OECD database and Neumark and Washer reports the average value for full-time minimum wage workers who are not subject to any derogations, as a percentage of average wages of full-time workers in the corresponding sector (see Immervoll, 2007, and Neumark and Washer, 2004).

Overall minimum wage regulation index 


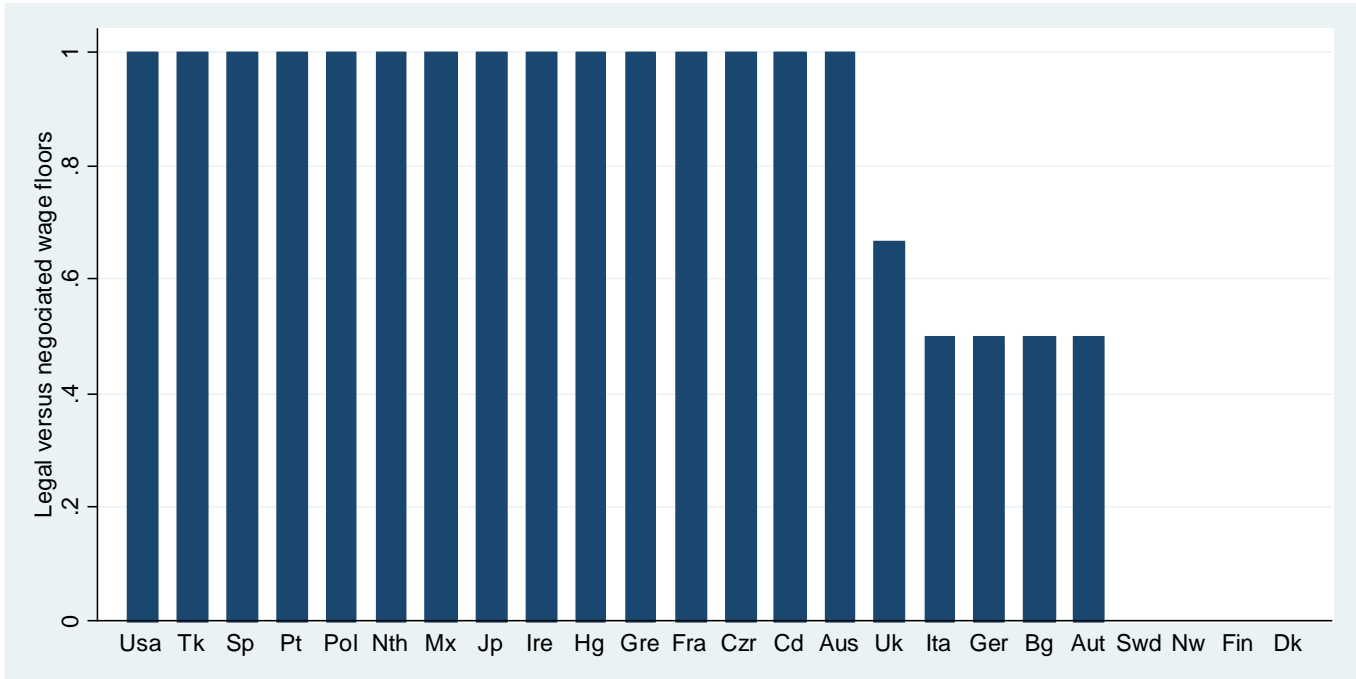

Figure 4: Legal statutory minimum wages or the degree of extension of negotiated wage floors. Period: 1980-2003.

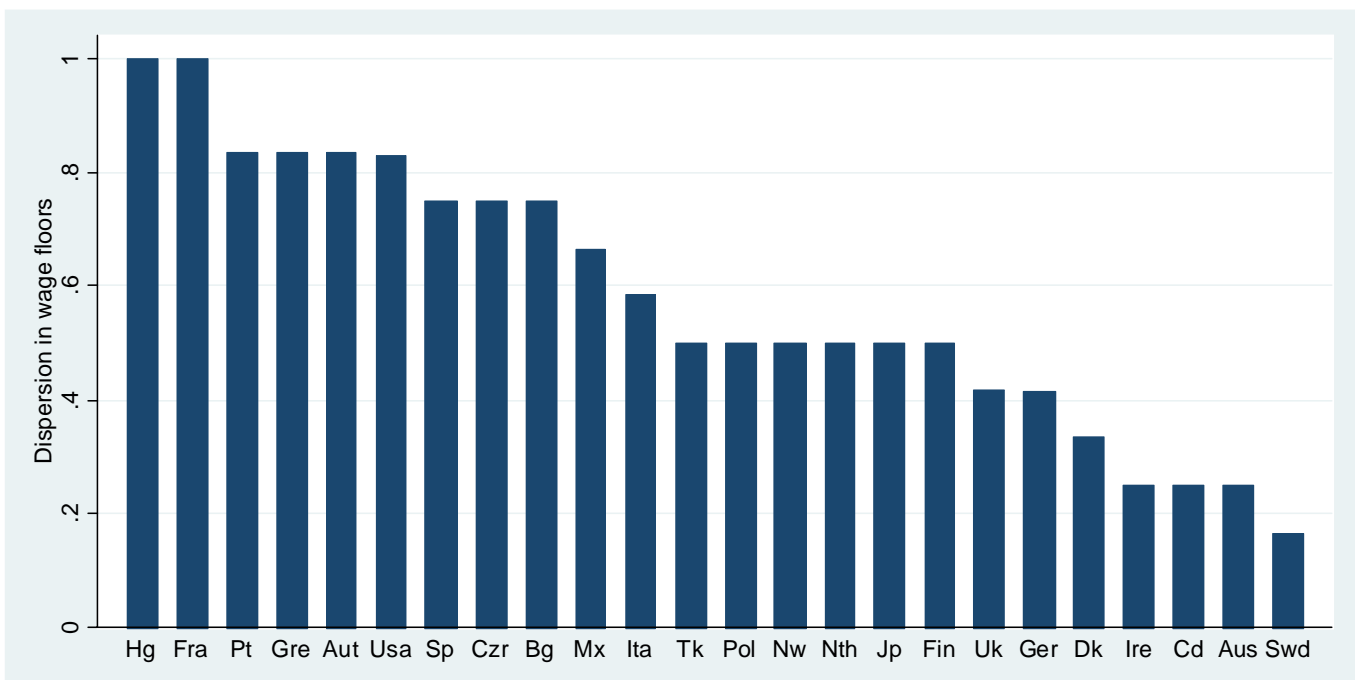

Figure 5: Degree of dispersion in wage floors by ages, qualifications, regions, sectors or occupations. Period 1980-2003. 
The overall measure of minimum wage regulation used in the following tables and figures, is simply the product minwage_legislation ${ }^{*}$ minwage_level.

\subsection{Measuring the quality of labor relations}

We measure the perceived level of cooperation in the labor market by the quality of the relationship between workers and managers. We first use the Global Competitiveness Reports, a survey sent out to thousands of executives each year across more than 50 countries. Among other questions, executives are asked to respond to the following statement: "Labor/employer relations are generally cooperative". Responses may vary from 1 for strong disagreement to 7 for strong agreement. One may of course worry about this only reflecting the perception of executives. We thus use additional information from the International Social Survey program 1999 (ISSP), which asks similar questions but for all categories of citizens. The question is the following: "In all countries there are differences or even conflicts between different social groups. In your opinion, how much conflict is there between management and workers in your country?" Responses are equal to 1 for "very strong conflict", 2 for "strong conflict", 3 for "not very strong conflict", and 4 for "no conflict at all". Henceforth we shall focus on workers' answers only, to contrast them with the executives' survey.

\subsection{Measuring union density}

We measure workers' involvement in unions by using the unionization data provided by the OECD at a yearly frequency since the 1960s. We also use data from Boeri et al. (2003) to track back the evolution of unionization rates since the early 1950s. We should be clear at this point that our primary focus is on workers' propensity to cooperate and to group into associations rather than rely on state intervention to guarantee their wage. In this regard, union density appears to be a more relevant indicator than union coverage rates. Obviously, the coverage indicator provides information regarding the bargaining power of unions, and as a matter of fact the role of unions in regulating wages becomes fairly high in some countries due to the automatic extension of negotiated wages to all sectors, even if the union density rate is really low. However the coverage indicator also captures the extent of state intervention in setting wages, since negotiated wages are extended by law to the different sectors of the economy. Thus this indicator does not truly reflect workers' preference for direct negotiations over the alternative of relying on state intervention. 


\section{Empirical evidence on beliefs and minimum wage regulation}

This section documents the empirical correlation between beliefs in cooperation and unionization rates on the one hand, and the extent of state regulation of minimum wages on the other hand. In particular, the model predicts that individuals rely directly on state intervention rather than on negotiation when beliefs about the scope of cooperation in the labor market are pessimistic. But conversely, by directly regulating wages, the state discourages individuals from engaging in social experimentation and thereby learning about the quality of labor relations. Here we provide evidence on this two-way relationship, and we also document on the dynamics of beliefs using survey data on confidence in labor institutions across successive waves of US immigrants who originate from countries with differing levels of labor market regulation.

\subsection{Correlation between the quality of labor relations and state regulation of wages}

Figure 1 reports the correlation between state regulation and the executives' beliefs, whereas Figure 6 reports the correlation between state regulation and workers' beliefs. In either case, the correlations are strongly negative, suggesting that beliefs in cooperation are more optimistic in countries with lower state regulation of the labor market.

Table 1 presents the results of the associated OLS regression. Column 1 reports the positive correlation between the quality of labor relation and union density in 2000. We measure the degree of cooperation by the GCR index which provides more observations, even if the correlation pattern is lower than that obtained with the ISSP index. Column 1 shows that the $\mathrm{R}^{2}$ is 0.33 , and union density is statistically significant at the one percent level. The second column shows that the correlation between the quality of labor relation and union density remains statistically significant at the five percent level when one controls for the unemployment rate and traditional labor market institutions taken from Nickell et al. (2001). Columns 3 and 4 report the strong negative correlation between the GCR index of the quality of labor relation and our index of state regulation of the minimum wage in the 2000s. The negative correlation is highly statistically significant at the one percent level even when one controls for the unemployment rate and other labor market institutions in Column 4, none of which appear to be statistically significant.

Now clearly, the causality between beliefs in cooperation and the extent of state regulation, can run both ways. On the one hand, one should expect higher support for state intervention in countries where beliefs in cooperative labor relations are weaker. Figure 7 documents this point by looking at the correlation between the fraction of population who believe that it is not the government's responsibility to set wages, and beliefs in cooperative labor relations. The 
Table 1: Quality of labor relations in OECD countries: 2000s. OLS estimates

\begin{tabular}{lcccc}
\hline \hline Dependent variable & \multicolumn{3}{c}{ Quality of labor relation } \\
\hline & $(1)$ & $(2)$ & $(3)$ & $(4)$ \\
\hline Unionization rate & $2.091^{* * *}$ & $2.140^{* *}$ & & \\
State regulation & $(.716)$ & $(.912)$ & $-3.339^{* * *}$ & $-2.821^{* * *}$ \\
of minimum wages & & & $(.876)$ & $(.827)$ \\
Unemployment rate & & $-7.301^{*}$ & & $-12.625^{* *}$ \\
& & $(3.802)$ & & $(4.170)$ \\
Replacement rate & & .555 & .422 \\
& & $(.941)$ & $(.860)$ \\
Benefit duration & & -.466 & & .235 \\
& & $(.570)$ & & $(.437)$ \\
Employment protection & & -.098 & & .152 \\
& & $(.289)$ & & $(.259)$ \\
Tax wedge & & -1.810 & & -.366 \\
$\mathrm{R}^{2}$ & & $(1.682)$ & & $(1.052)$ \\
Observations & .54 & 18 & .46 & .74 \\
\hline
\end{tabular}

indicator of support for wage regulation by the state is drawn from the 1996 publication of the International Social Survey program database. There, we focus on the following question: "Here are some things the government might do for the economy. Please show which actions you are in favor of and which you are against: control wages by law?". The answers are ranked from 1, for a strong agreement, to 5 for a strong disagreement. Figure 7 shows, on the vertical axis the mean answer to this question for each country, and on the horizontal axis the index of beliefs in cooperative labor relations. The correlation between these two variables turns out to be strongly negative with 41 percent of the variation in public support for state regulation of wages across countries being associated with differences in beliefs about the cooperative nature of labor relations.

\subsection{History dependence in OECD countries}

Our model predicts history dependence in beliefs about cooperation: in particular, for given initial beliefs, different cooperative equilibria might emerge depending upon the history of successes or failures of negotiations between unions and firms. Crouch (1993) provides overwhelming evidence of such historical dependence in the development of unions and the quality of labor relations.

Unionization rates were quite comparable across European countries at the end the 19th century, ranging from 3 percent in Netherlands, 4 percent in Norway, 5 percent in Sweden, 6 


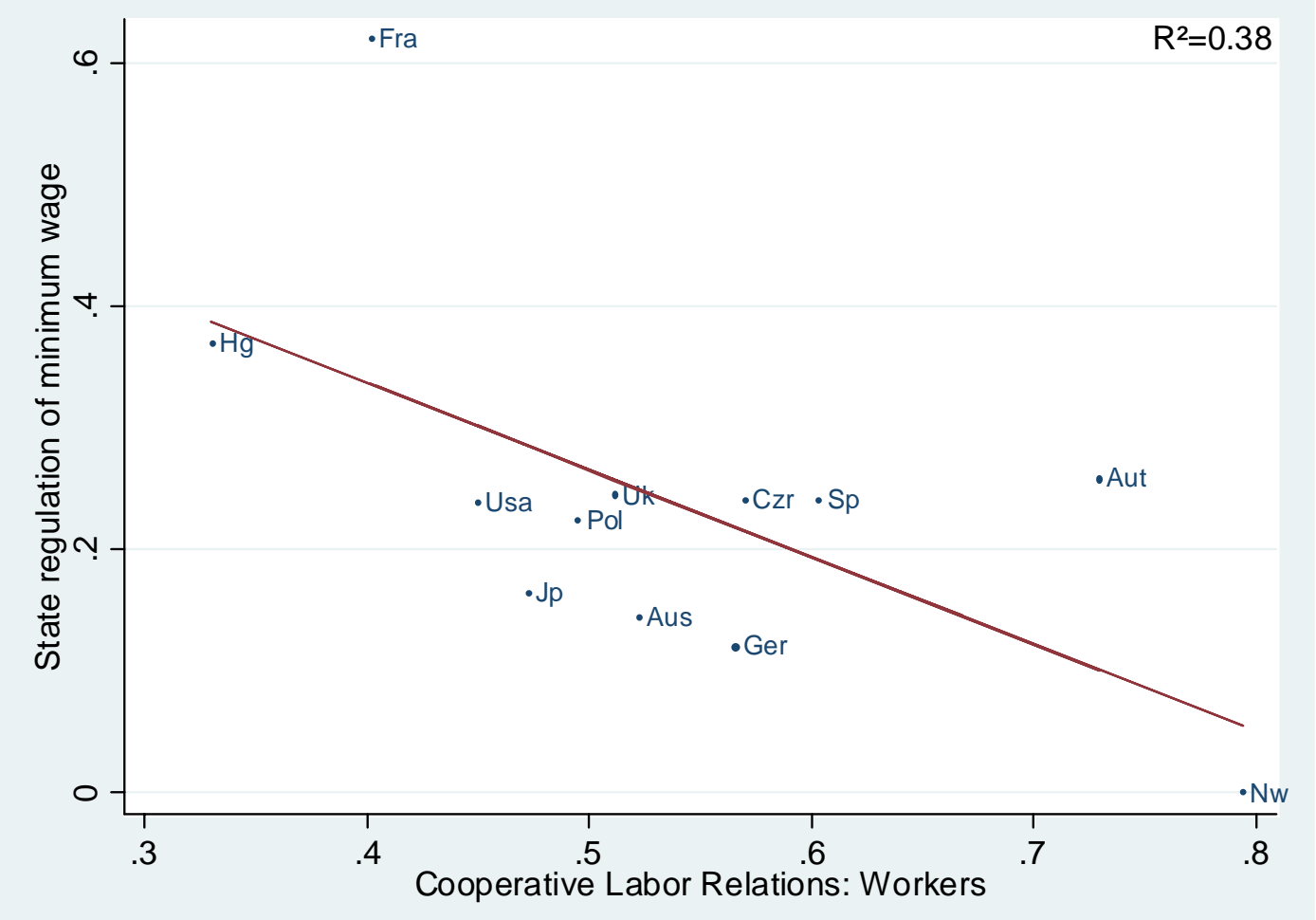

Figure 6: Correlation between State regulation of minimum wages and Workers' beliefs in Cooperative labor relations. Source: ILO, OECD, and ISSP 1999 database. 


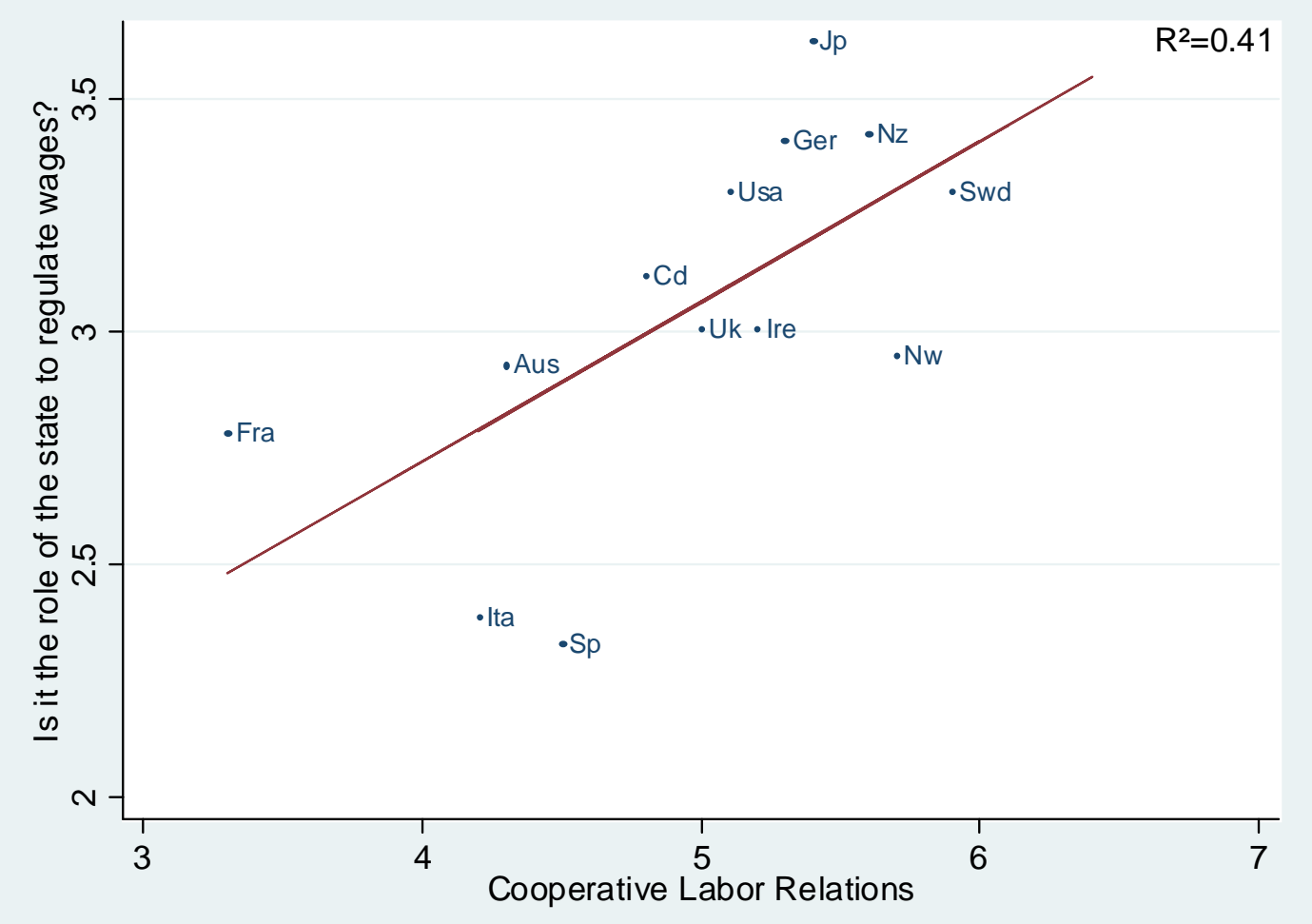

Figure 7: Correlation between the extent of cooperative labor relations (GCR 1999) and the share of people who disagree with the folling question: "Is it the role of the government to directly set wages?" (ISSP 1996). 
percent in France to 13 percent in UK and Denmark. But the development of unions and of cooperation on the labor market has been deeply influenced by the subsequent social history of agreements and conflicts between firms and union workers.

Remarkably enough, labor relations were fairly hostile in Denmark in the 19th century, and the Great Lock-Out of 1898 is probably the single biggest industrial dispute in Europe over the 19th century. However this dispute led to a social pact between organized labor and firms, whereby unions would recognize the private property of firms by capitalists, and in exchange, capitalists and workers unions would negotiate wages directly on a bilateral basis, without any state intervention. Ever since, the unionization rate has steadily risen in Denmark and this country displays one of the highest quality of labor relation in the 2000s. The same picture holds for Belgium, Austria, Germany, United Kingdom and Sweden. According to Crouch, labor relations in these countries used to be highly conflictual. But precisely this encouraged employers and the state to design institutions aimed at involving unions in the regulation of labor markets in order to contain social disruption. This evolution pattern departs from that of France where central governments, whether from the right or from the left, have remained traditionally suspicious vis-a-vis unions and have therefore privileged centralized negotiations at the government level, for example during the Front Populaire in 1936 or more recently with the Grenelles Agreement in the aftermath of May 1968.

Table 2 provides quantitative evidence regarding the impact of the historical state involvement on the development of the quality of labor relations. There, we bear on Crouch's analysis of the attitudes of the states towards unions in Europe during the 19 th century ${ }^{19}$ Crouch classifies states in three categories. The first category comprises states that were most hostile to the development of unions and consequently more prone to directly regulate labor market and settle disputes through centralized decisions. This group includes the main catholic strongholds in Europe, namely France, Italy, Spain and Portugal. Crouch account for this fact by stressing that in these countries the central government needed to assert its authority over the Catholic church and to confront all forms of organized interests, including worker organizations. The second category comprises five countries where the state was rather neutral vis-a-vis labor organization and would consequently let them directly with firms. This is the case of Belgium, Denmark, Norway, Sweden, Finland, UK and Ireland. Finally, the third category consists of countries where the State would encourage union involvement in the regulation of labor markets. This category includes Austria, Germany, Netherlands, Switzerland. In particular, the Austrian and German governments were first to set up elected workers commissions to run pensions and social

\footnotetext{
${ }^{19}$ Blanchard and Philippon (2006) show that these initial attitudes of the states towards union might also explain current unemployment rates.
} 
insurance schemes as of the 1880s.

Table 2 shows the correlation between the 1999 GCR index of quality of labor relation and the initial interplay between the State and unions. The cluster of countries with hostile states is taken as the reference. Table 2 - Column 1 shows that the quality of labor relation in 1999 is positively correlated with the fact of initially belonging to the second or third category of neutral and supportive states towards unions. The OLS coefficients are statistically highly significant and the $\mathrm{R}^{2}$ is .55. Table 2 - Column 2 shows that the correlation remains statistically significant when one controls for contemporaneous values of unemployment and other labor market institutions, none of these latter variables being statistically significant.

Table 2: Quality of labor relations in OECD countries in 2000s and attitudes of the state towards unions in the 19th century

\begin{tabular}{ccc}
\hline \hline \multicolumn{2}{c}{ Dependent variable } & \multicolumn{2}{c}{ Quality of labor relations GCR index } \\
\hline State attitudes towards & & $(2)$ \\
early unions in the 19th & & \\
Hostile $=1$ & Reference & Reference \\
Neutral $=1$ & $1.121^{* * *}$ & $1.122^{* *}$ \\
& $(.301)$ & $(.425)$ \\
Supportive $=1$ & $1.516^{* * *}$ & $1.754^{* *}$ \\
& $(.447)$ & $(.652)$ \\
Unemployment rate & & -6.549 \\
& & $(5.709)$ \\
Replacement rate & & 1.148 \\
& & $(.950)$ \\
Benefit duration & & -1.720 \\
& & $(1.141)$ \\
Employment protection & & -.258 \\
& & $(.603)$ \\
Tax wedge & & -1.864 \\
$\mathrm{R}^{2}$ & & $(2.040)$ \\
Observations & .55 & .74 \\
\end{tabular}

\subsection{History dependence: the beliefs of US immigrants}

Here we provide additional quantitative evidence on the influence of past minimum wage policies and past unionization rates on current beliefs towards labor relations. For that purpose, we use the General Social Survey database which provides information on Americans' attitudes towards labor institutions as well as detailed information on the country of origin of their ancestors and the wave of immigration to which they belong. This database covers the period 1972-2004 and 
provides information on the birth place and the country of origin of the respondent's forebears since 1977. The GSS variable for the country of origin reads as follows: "From what countries or part of the world did your ancestors come?". Origins cover nearly all European countries.

The GSS also asks whether the respondent has confidence in labor unions, namely: "Would you say you have a great deal of confidence, only some confidence, or hardly any confidence at all in organized labor institutions?". We measure the extent of confidence in unions with a dummy variable equal to 1 if the respondent answers "a great deal of confidence", and to zero otherwise. We also have information on whether the respondent belongs to a labor union or not.

We use the information about the past union densities and the existence of statutory minimum wage in the home country from the early 1950s. Note that we do not have data on the level of minimum wage, but only on the existence of statutory wage floor in some countries such as France or the United States. To assess the effect of minimum wage institutions on current attitudes towards unions, we focus on second and first generations of Americans born after 1950, and whose parents or themselves are likely to have been influenced by these institutions. In order to get interpretable results, we restrict attention to countries of origin with more than 15 observations, which leaves us with the following set of countries of origins: Austria, France, Germany, Ireland, Italy, Japan, Netherlands, Sweden, and the United Kingdom. The data description are reported in the Appendix.

Table 3 - Line (I) reports the probit marginal estimates of the effect of past levels of unionization rate in the home country on current level of trust in unions, and on the probability of belonging to a union. We control for age (age squared), gender, number of years of education, income categories, and the number of years of education of the parents. Standard errors are clustered at the level of the country of origin. Column (1) shows a strong correlation between past union rates in the country of origin and the probability that the respondent has confidence in unions now. The relation is statistically significant at the one percent level. The size of the effect is also large, with a one percent increase in past union rates in the home country being associated with 0.18 percent increase in the probability that the respondent has a great deal of confidence in this institution. Column (2) reports the correlation between past unionization rate in the home country and the current probability of belonging to a union. The correlation is also positive and statistically significant at the one percent level. Remarkably enough, past union density is a main predictor of current unionization behavior, and its effect is one order of magnitude higher than most other individual characteristics. ${ }^{20}$

\footnotetext{
${ }^{20}$ Similar results about the influence of the country of origin on beliefs are found in Rice and Feldman (1997) and many others. See Algan and Cahuc (2006), Fernandez and Fogli (2005), Guiso et al. (2006), Fernandez (2007) for a presentation of this literature.
} 
Table 3 - Line (II) reports the correlation between past regulation of minimum wages by the state in the country of origin and current unionization behavior in the United States. As reported in Column (I), that the country of origin had a statutory legal minimum wage in the early 1950s strongly reduces the probability that the respondent trusts unions.

Table 3: Historical labor market institutions in the home country and current unionization attitudes of Americans by country of origin. Probit estimates

\begin{tabular}{lcc}
\hline \hline & Confidence in unions (=1) & Union membership $(=1)$ \\
& $(1)$ & $(2)$ \\
\hline Union density $(\mathrm{I})$ & $.186^{* * *}$ & $.248^{* *}$ \\
in home country 1950 & $(.057)$ & $(.113)$ \\
$\mathrm{N}$ & 1175 & 1015 \\
$\mathrm{R}^{2}$ & .030 & .019 \\
\hline Legal minimum wage (II) & $-.447^{* * *}$ & -.192 \\
in home country 1950 & $(.139)$ & $(.178)$ \\
$\mathrm{N}$ & 928 & 871 \\
$\mathrm{R}^{2}$ & .054 & .021 \\
\hline \multicolumn{2}{c}{ Marginal effects with robust standard error GSS : ${ }^{* * *}: 1 \%,{ }^{* *}:$} & $5 \%,{ }^{*}: 10$ \\
Additional controls: gender, age, education, income category \\
\hline
\end{tabular}

\subsection{Experimentation and the dynamics of beliefs in cooperation}

Our model stresses that the historical dependence of current beliefs upon past minimum wage regulations, runs through a learning process and the resulting updating of beliefs. In this section, we provide evidence of this updating of beliefs.

To measure the evolution of beliefs across generations, we use information on the waves of immigration of the respondents. Respondents are asked if they are born in the United States and how many of their parents and grand-parents were born in the country. The answer to the question on parents birthplace is scaled at 0 if both parents are born in the US, at 1 if only the mother is born in the US, and at 2 if only the respondent's father is born in the country. The answer on grand-parents birthplace is scaled from 0 to 4 indicating the number of grandparents born in the US. To get representative samples, we merge the first and second generations Americans into one group, and the third and fourth generations Americans into another group.

To assess the beliefs about unions in the home country, we use the respondents' answers to the following question from the World Values Survey database (which is quite similar to the question in GSS database): "Do you have a great deal of confidence, quite a lot of confidence, not very much confidence or none at all confidence in unions?". We create a dummy variable 
equal to one if the respondent answers "a great deal of confidence" or "quite a lot of confidence", and to zero otherwise.

Table 4 reports the probit estimates of the probability that Americans do have confidence in unions. We focus on first and second generation Americans. The coefficients associated with the country of origin correspond to the marginal probit estimates. To explore further the specific role of the country of origin in the formation of beliefs, we control for individual characteristics, including age, age squared, employment status and income category. Americans with Swedish origins are taken as the reference group. The first result is that the country of origin plays a statistically significant role on the level of confidence in unions. All the country of origin dummies are statistically significant at the one percent level. Moreover, the coefficients are economically sizeable. For instance, the probability that Americans with French origins have confidence in unions is 10 percent lower than for Americans with Swedish origins.

We then explore the extent to which these beliefs are consistent with those that prevail in the country of origin and we are interested in their rate of convergence. Figure 8 reports the correlation between the current level of confidence in unions in the country of origin and the corresponding level of confidence of the first and second generations Americans originating from that country. The horizontal axis reports the fraction of individuals who have confidence in unions in the country of origin, whereas the vertical axis reports the fraction of Americans who trust unions depending on their country of origin. The figure shows a strongly positive correlation between these two variables, equal to 0.38, with 20 percent of the variation in Americans' beliefs towards unions being associated with differences in beliefs across countries of origin. Moreover, the variance in Americans' beliefs in unions across different countries of origin is quite large, with the share of confidence in unions ranging from 0.05 percent to 0.25 percent.

We then assess the convergence in beliefs by focusing on older waves of immigration. Figure 9 reports on the vertical axis the level of confidence in unions of third and fourth generations Americans, and on the horizontal axis the level of confidence in the country of origin. In contrast to Figure 8 above, here the correlation between the beliefs of third and fourth generations Americans and the beliefs in the corresponding home country is close to zero and no longer significant. Moreover, the variance in the level of confidence across third and fourth generations Americans from different countries of origin is much lower compared to the first and second generations Americans, the range of variation now lying in the interval $[0.075,0.145]$. 


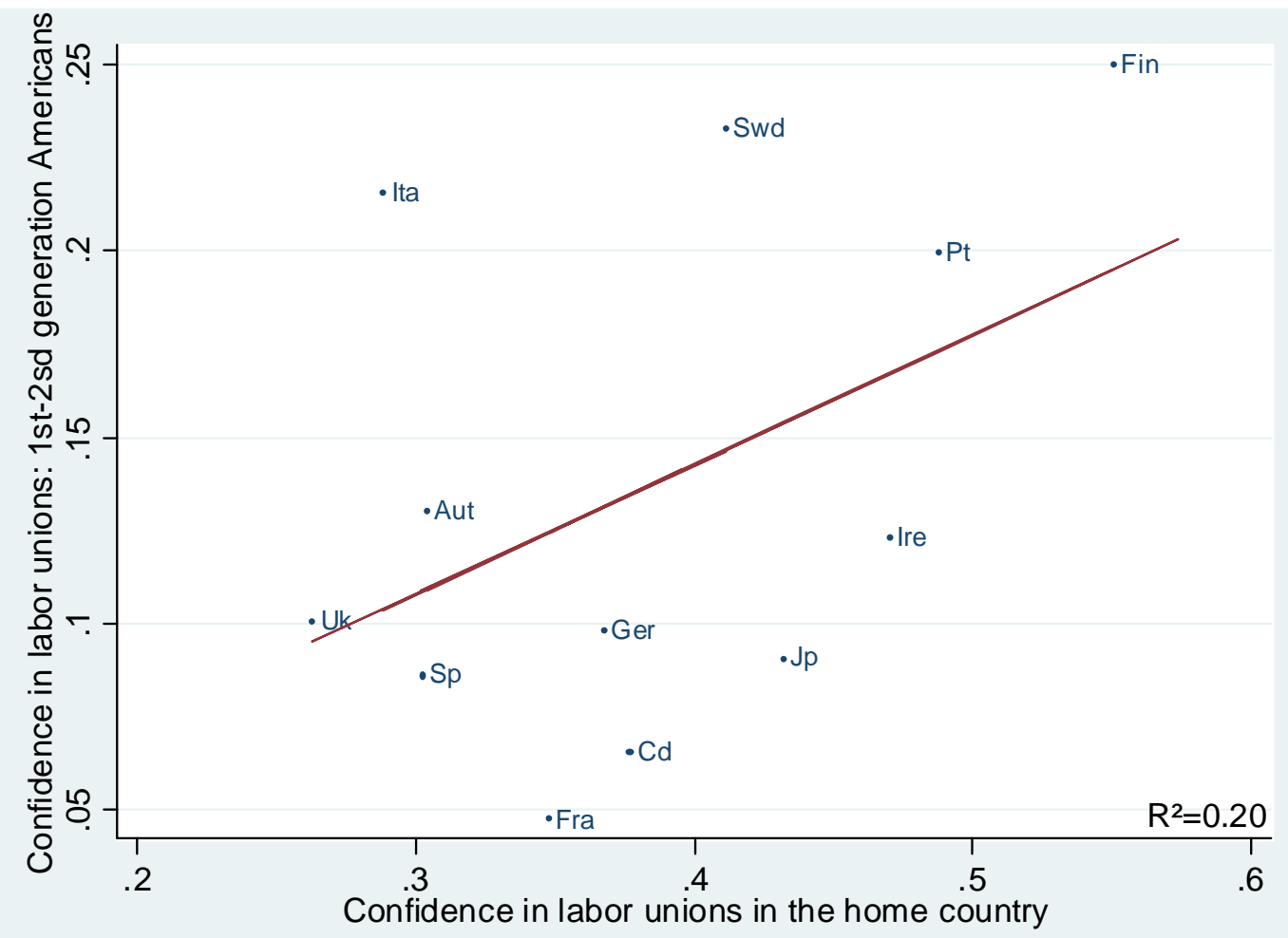

Figure 8: Confidence in unions in the home country and by Americans of first or second generations. Source: WVS 1980-2000, GSS 1977-2004. 


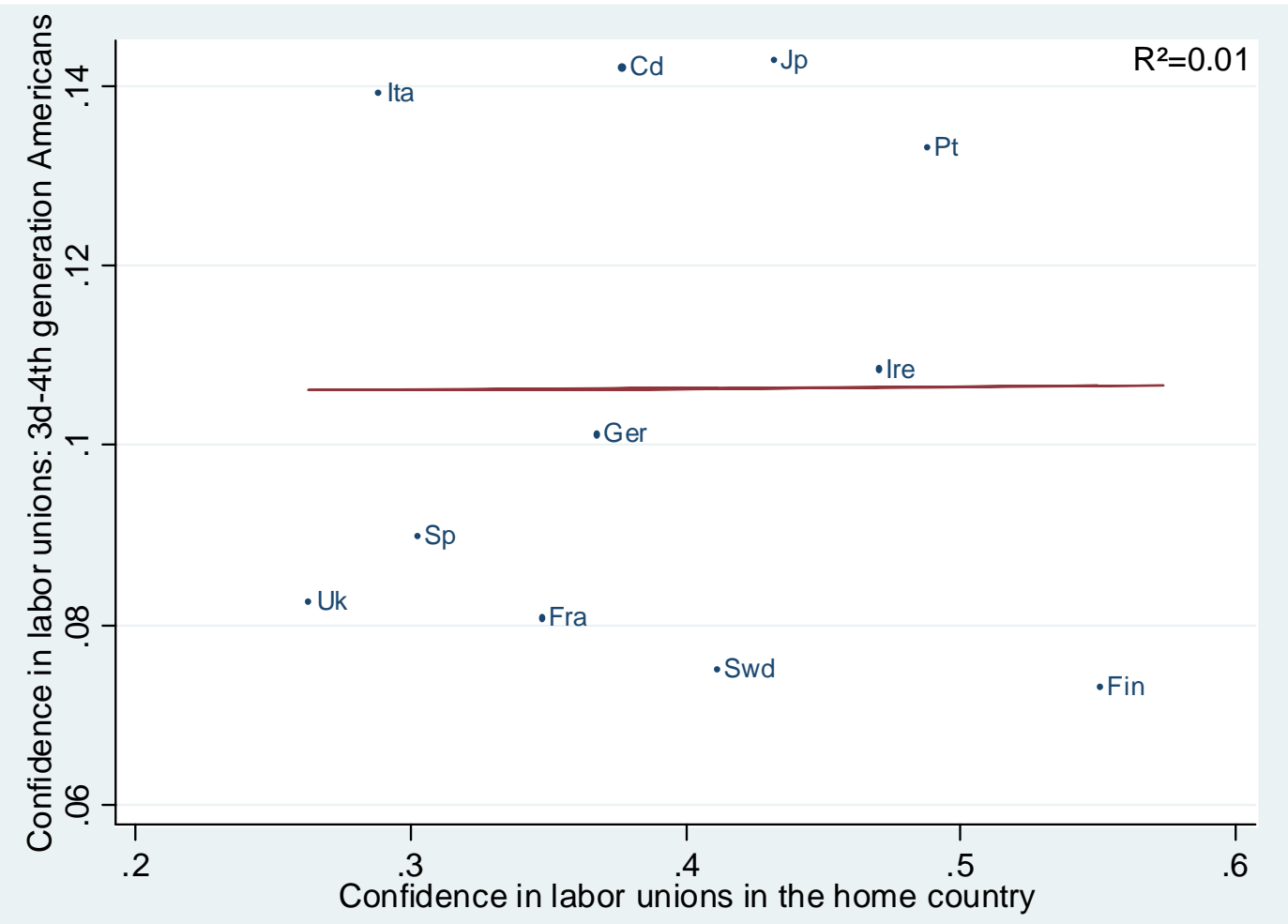

Figure 9: Confidence in unions in the home country and by Americans of third or fourth generations. Source: WVS 1980-2000, GSS 1977-2004. 
Table 4: Confidence in unions of 1st and 2sd generation Americans by country of origin. Marginal effects

\begin{tabular}{lcc}
\hline \hline & \multicolumn{2}{c}{ Confidence in unions $=1$} \\
& Coeff & Std Error \\
Austria & $-.071^{* * *}$ & $(.004)$ \\
Canada & $-.108^{* * *}$ & $(.003)$ \\
Finland & $-.028^{* * *}$ & $(.007)$ \\
France & $-.109^{* * *}$ & $(.008)$ \\
Germany & $-.091^{* * *}$ & $(.007)$ \\
Ireland & $-.071^{* * *}$ & $(.004)$ \\
Italy & $-.043^{* * *}$ & $(.009)$ \\
Japan & $-.088^{* * *}$ & $(.013)$ \\
Portugal & $-.068^{* * *}$ & $(.019)$ \\
Spain & $-.099^{* * *}$ & $(.012)$ \\
Sweden & \multicolumn{2}{c}{$(.003)$} \\
United Kingdom & $-.089^{* * *}$ & Reference \\
Pseudo- ${ }^{2}$ & \multicolumn{2}{c}{921} \\
Observations & \multicolumn{2}{c}{} \\
\hline Marginal effects with robust standard error. GSS database \\
Controls: age, age2, education, employment status, income \\
***:1\%, **: 5\%, *: $10 \%$ \\
\hline
\end{tabular}

\section{Unionization and minimum wage regulation}

In this section we document the negative correlation between minimum wage regulation and union density predicted by the model. We show that this correlation holds in both, crosssectional and panel cross country regressions. We also find the same negative correlation in cross-US states panel regressions.

\subsection{Cross-country correlations}

Figure 10 depicts the cross-country correlation between workers' involvement in unions and the degree of state regulation of wage floors in OECD countries on average over the period 19802003. We construct the composite index of the extent of state regulation of minimum wages by combining information on the stringency of the legislation minwage_legislation and information on the minimum wage levels minwage_level. The global composite index minwage is defined as the product between the two indexes minwage_legislation and minwage_level.

The vertical axis shows the average union densities by country over that period. Nordic countries display the highest unionization rates over that period, with a 82 percent rate in Sweden and a 77 percent rate in Denmark. Countries such as Austria and Germany fall in the 
middle part of the picture with union density rates at around 40 percent. Anglo-Saxon countries like United-Kingdom or Canada, belong to the same middle group. And Mediterranean countries show the lowest unionization rates, with less than $10 \%$ in France or Spain. Note that Italy is a clear outlier, with a unionization rate close to $40 \%$.

The horizontal axis shows the composite index minwage index measuring state regulation of minimum wage. As we can see on the Figure, the correlation between the composite index of wage regulation and unionization rates is strongly negative. Nordic countries which have very high unionization rates also display the weakest state regulations. There is no legal minimum wage in these countries: wage floors are negotiated at industry level, and there is a substantial amount of dispersion in wage floors across regions, industries, qualifications and ages. The same picture holds for Continental countries like Austria and Germany, which combine relatively high union density rates and the absence of statutory minimum wage. In contrast, Mediterranean countries display the highest level of state intervention to set minimum wages. Countries like France not only set minimum wages by law but they also limit the scope for derogations and for direct negotiations by social partners. The one clear exception among Mediterranean countries is Italy. This country does not have a statutory minimum wage, hence its lower ranking in terms of our index of state regulation. However, in Italy, wage floors negotiated at the industry level are automatically extended to other industries. Finally, we see noticeable differences within the group of Anglo-Saxon countries. Those with high index of state regulation like the United States are also characterized by low union densities. In contrast, Great-Britain appears to have a relatively high union density and a lower index of state regulation, which in turn results both, from unions being so powerful prior to the 1980s and the fact that wage floors were negotiated by wage councils before 1993 .

We explore this correlation pattern further by running OLS regressions between unionization rates and our index of state regulation of the minimum wage. To maximize the number of observations, we run this estimation over three time periods, computing the average of the composite index respectively over the periods 1980-84, 1990-94 and 2000-2003. We also look at the correlation between unionization rates and the two sub-indexes which capture respectively the existence of a legal statutory minimum wage and the degree of dispersion in minimum wages. We evaluate the correlations between unionization and the two sub-indexes taken separately, and between unionization and the interaction terms between these sub-indexes and the indicator measuring the level of minimum wages.

Table 5- Column (1) reports the cross-country estimated correlation between unionization rates and the extent of state regulation of minimum wage over the period 1980-2003. This correlation is negative, and statistically significant at the 1 percent level. Almost 45 percent of 


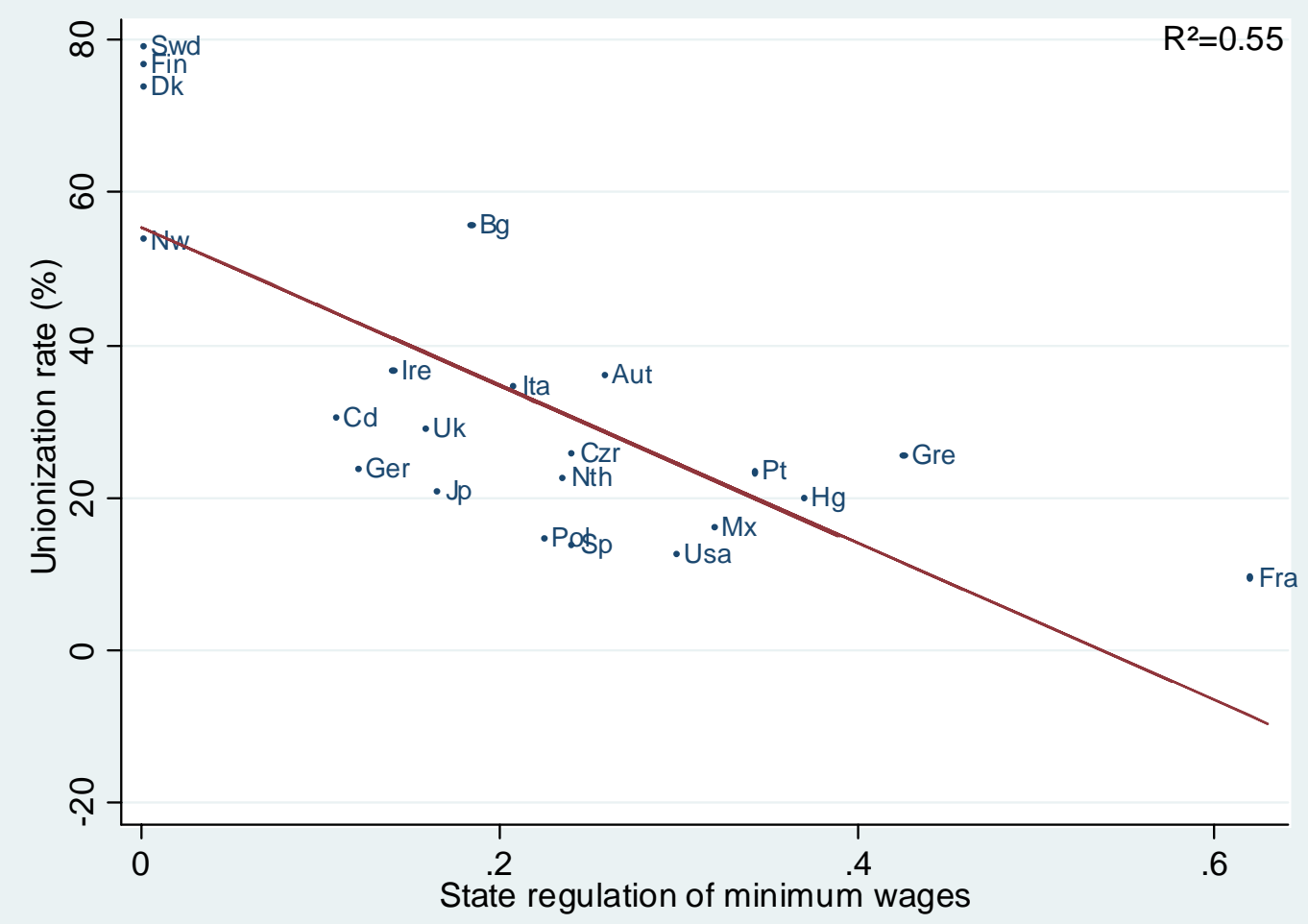

Figure 10: Union density and the index of state regulation of minimum wage. The index includes the stringency of the legislation and of the level of minimum wages. Period 1980-2003. Source: OECD and ILO. 
the cross-country variation observed in the state regulation index is associated with differences in unionization rates. Table 5-Columns (2)-(5) show that the same negative correlation pattern holds when we look at the two sub-indexes, or when we combine these sub-indexes with the level of minimum wage. Overall, this first table suggests a strong negative correlation between unionization rates and the extent to which the state strictly regulates minimum wage.

Table 5: Cross-country correlation between state regulation of minimum wage and union density: OECD countries 1980-2003. OLS.

\begin{tabular}{lccccc}
\hline \hline Dependent variable & & \multicolumn{3}{c}{ State regulation of minimum wages } \\
& $\begin{array}{c}\text { Composite } \\
\text { index }\end{array}$ & $\begin{array}{c}\text { Legal } \\
(1)\end{array}$ & $(2)$ & $\begin{array}{c}\text { Dispersion } \\
\text { Legal } \\
* \text { Level }\end{array}$ & $\begin{array}{l}\text { Dispersion } \\
* \text { Level }\end{array}$ \\
& $(1)$ & & $(4)$ & $(5)$ \\
\hline Unionization rate & $-.518^{* * *}$ & $-1.568^{* * *}$ & $-.587^{* * *}$ & $-.606^{* * *}$ & $-.214^{* * *}$ \\
$\mathrm{R}^{2}$ & $(.083)$ & $(.156)$ & $(.134)$ & $(.099)$ & $(.099)$ \\
Observations & .441 & .658 & .262 & .442 & .102 \\
\hline
\end{tabular}

\subsection{Time variation}

The negative correlation between union density and state regulation of minimum wage also appears to hold over the time period 1980-2003 within countries. Countries which have experienced the sharpest decline in union densities are also those that have tightened state regulation of wage floors the most. A striking example is the United Kingdom where wage floors used to be set by unions before the country embraced a statutory minimum wage in 1999 to offset the decline of union bargaining power. What happened is that the unionization rate had fallen from $50 \%$ in 1980 to less than 30\% in the late 1990's, in part as a result of Margaret Thatcher's crackdown on strikes in 1982. Meanwhile, the political pressure from the workers to get a legal minimum wage has gained momentum, leading Tony Blair to introduce a statutory minimum wage. Of course the negative relationship can run both ways. It might be the case that union densities have mainly increased in countries where statutory minimum wages are absent, like Scandinavian countries, because workers cannot rely on state regulation and have strong incentives to coordinate themselves to defend their wages. Conversely, the decline in union densities could have triggered changes in minimum wage legislations.

Table 6 reports the within correlation between the evolution of the composite index of state regulation of minimum wages and the evolution of union density. We focus on two time periods, the early 1980s and the early 2000s, to allow for enough time variation. The regressions control for country fixed effects and linear time trends. 
Table 6 - Column (1) reports the within correlation between contemporaneous values of unionization rate and state regulation of minimum wage. A strong negative correlation shows up, the effect being statistically significant at the one percent level. Table 6 - Column (2) reports the correlation between the index of state regulation of minimum wage and the lagged value of union density. When looking at state regulation in the early 1980's, we use union density in the early 1970s (1970-74). The estimated coefficient is strongly negative and statistically significant at one percent level. Lower unions rates during the 70's are associated with more stringent minimum wage regulation by the state a decade or two later. This result might account for the rising political support in favor of an increase in statutory minimum wages in countries where the bargaining power of unions is declining. This is typically the case of the United States, as we show below.

Table 6: Time variations in unionization rates and state regulation of minimum wages. OECD countries: 1980-2003. OLS

\begin{tabular}{lcc}
\hline \hline Dependent variable & \multicolumn{2}{c}{$\begin{array}{c}\text { State regulation of minimum wages } \\
\text { (Composite index) }\end{array}$} \\
& $(1)$ & $(3)$ \\
\hline Unionization rate & $-1.089^{* * *}$ & \\
& $(.312)$ & $-0.528^{* *}$ \\
Unionization rate $(-1)$ & & $(.262)$ \\
Country fixed effects & Yes $^{* * *}$ & Yes $^{* * *}$ \\
Time dummies & Yes $^{* * *}$ & Yes $^{* * *}$ \\
Observations & 36 & 36 \\
\hline
\end{tabular}

\subsection{Evidence from the United States}

The United States were the first country to implement a statutory minimum wage after the enactment of the Fair Labor Standard Act in 1938. As the title of the act makes it clear, the statutory minimum wage was aimed at offsetting the negative effects of the Great Depression by granting workers a fair wage guarantee. The historian Jonathan Grossman relates the following story about the birth of the Fair Act: "While President Franklin Roosevelt was in Bedford, Mass., campaigning for reelection, a young girl tried to pass him an envelope. But a policeman threw her back into the crowd. Roosevelt told an aide, "Get the note from the girl." Her note read, I wish you could do something to help us girls.... We have been working in a sewing factory,... and up to a few months ago we were getting our minimum pay of $\$ 11$ a week... Today the 200 of us girls have been cut down to $\$ 4$ and $\$ 5$ and $\$ 6$ a week. To a reporter's question, the President replied, "Something has to be done about the elimination of child labor and long hours 
and starvation wages." " (in Public papers and Addresses, 1936).

Similarly, since the 1990s, partly as a result of workers' difficulty to organize and defend wages, the United States have experienced a steady rise in minimum wages at the state and federal levels. The federal minimum wage remained unchanged at $\$ 3.35$ from 1981 to 1990 , when it was raised up to $\$ 3.80$. During the eighties, states such as Alaska, Connecticut and Massachusetts began to set a higher minimum wage and by 1989, 15 states had their minimum wage higher than the federal one. After the rise in federal minimum wage up to $\$ 4.25$ in 1991 , as many as 10 states (and DC) began to implement floors above the federal level. A considerable increase in the federal level up to $\$ 5.15$ in 1997 reduced the number of states with floors higher than the federal minimum. From 1997 to July 2007, the federal minimum wage has remained stable at $\$ 5.15$. But no less than 32 states began to set their minimum wage above the federal minimum wage. Since 2007, the Federal government is catching-up by raising the federal level up to $\$ 5.85$ in 2007, and it should raise it again up to $\$ 7.25$ in July 2009 .

Figure 11 shows that this evolution pattern of minimum wage is negatively correlated with the evolution pattern of union density since the 1990s. The horizontal axis shows time differences in the evolution of the federal minimum wage, while the vertical axis reports the time differences in the evolution of the average unionization rate in the United States. We smooth out short run fluctuations by taking five year averages in 1990, 1995, 2000, and a three year average for the period 2005-2007. While average union density has dropped by 50 percent over the whole period, the federal minimum wage has increased by 50.6 percent over that same period. The figures presented in Appendix D report the same evolution pattern of minimum wage and union density at the state levels. It turns out that all states are characterized by a negative correlation between the evolution of union density and that of the minimum wage. Naturally, this dynamics could be driven by specific state effects and specific state time trends. We thus explore further this correlation pattern by running OLS estimates that control for these factors.

Table 7 shows the results from regressing minimum wages over union densities in the crossUS-state panel. In this table, we control for state fixed effects and state specific time trends. We are thus looking at the within correlation between minimum wage levels and union rates. The estimates cover the period 1997-2007, when a large bulk of states decided to increase their minimum wage. Table 7 - Column (1) and (2) report the results for states that had a minimum wage above the federal level between 1997 and 2007. We see strongly negative coefficients, which are statistically significant at the one percent level in the specification with state fixed effects (Column (1)) and at the 5 percent level in the specification including state specific trends (Column (2)). The coefficients are also economically significant. The first specification suggests that a 1 dollar increase in the minimum wage is associated with a 12 percent decrease in union 


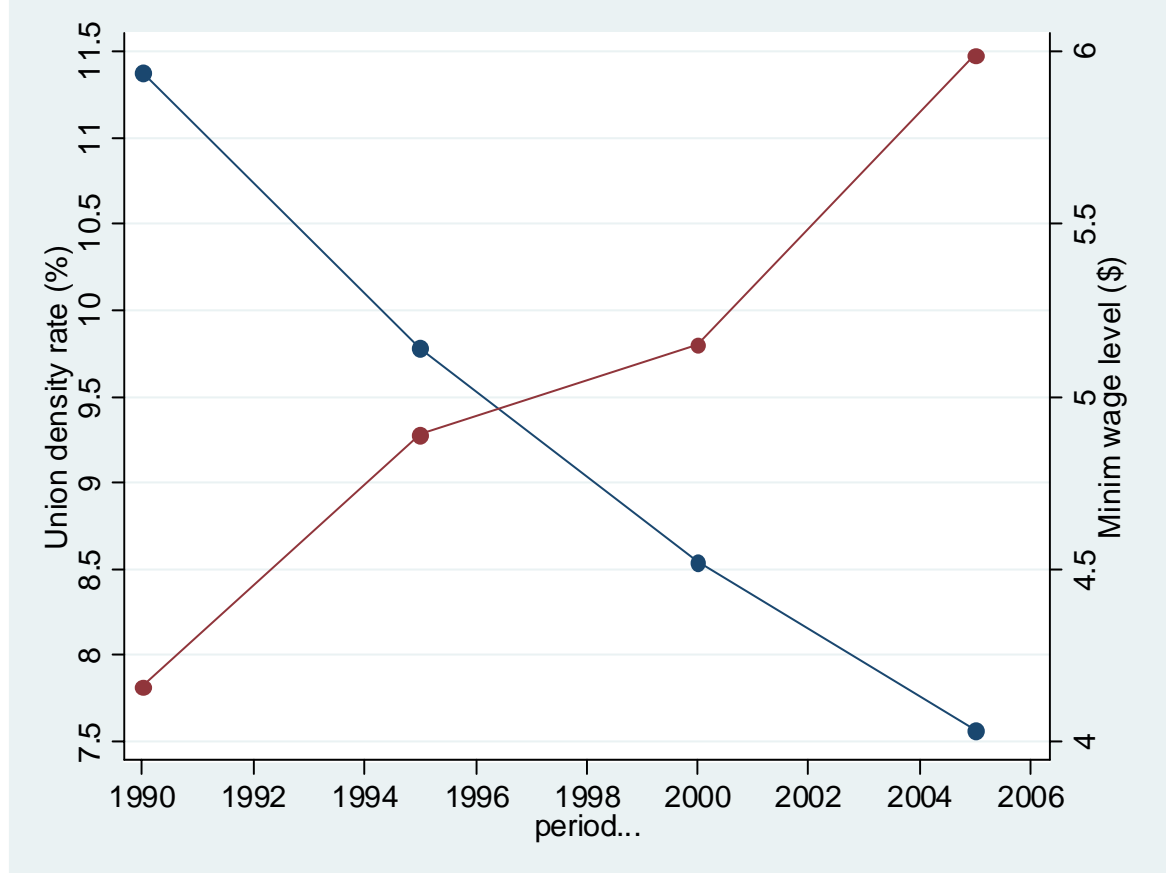

Figure 11: Evolution of the federal minimum wage and the average union rate (private sector) in the United States.

density. Table 7 - Column (3) - (4) report the estimates for all states, including states which have sticked to the federal minimum wage level during that period. The correlations between minimum wage levels and union densities remain negative and statistically significant. But these coefficients are smaller than in columns (1) and (2) respectively, suggesting that the decrease in union density has been higher in states which have increased their minimum wages above that of the federal state.

\section{Conclusion}

In this paper we have argued that in countries with highly cooperative labor relations and high unionization rates, the state is less prone to regulate the minimum wage. In such countries, there is no need for a legal minimum wage because social partners negotiate wages directly. Conversely, in countries with strong state regulation of the minimum wage, incentives for social dialogue are low and so is union density, as strong state regulation of the minimum wage crowds out social experimentation and learning about cooperation. This crowding out effect progressively undermines cooperation and leads economies towards steady-state equilibria with bad labor 
Table 7: Time variations in union density and wage floors in the United States: 1997-2007.

\begin{tabular}{|c|c|c|c|c|}
\hline \multirow[t]{2}{*}{ Dependent variable } & \multicolumn{2}{|c|}{$\begin{array}{l}\text { Minimum wages } \\
\text { (States with wage floors } \\
\text { higher than the federal one) }\end{array}$} & \multicolumn{2}{|c|}{$\begin{array}{l}\text { Minimum wages } \\
\text { (All States) }\end{array}$} \\
\hline & (1) & $(2)$ & $(3)$ & (4) \\
\hline Union density & $-.125^{\text {*** }}$ & $-.038^{* *}$ & $-.120^{* * *}$ & $-.030^{* *}$ \\
\hline Union density & $(.017)$ & $(.017)$ & $(.016)$ & $(.016)$ \\
\hline State fixed effects & $\mathrm{Yes}^{* * *}$ & $\mathrm{Yes}^{* * *}$ & No & $\mathrm{Yes}^{\text {*** }}$ \\
\hline State specific trends & No & $\mathrm{Yes}^{* * *}$ & No & $\mathrm{Yes}^{* * *}$ \\
\hline $\mathrm{R}^{2}$ & .63 & .85 & .63 & .88 \\
\hline Observations & 430 & 430 & 451 & 451 \\
\hline
\end{tabular}

relations and high minimum wage regulations.

This in turn suggests that state regulation of the minimum wage can have long run costs that have been largely disregarded by the economic literature so far. The importance of the contrast between Scandinavian countries, which display good labor relations and good labor market performance on the one hand, and Mediterranean countries with poor labor relations and poor labor market performance on the other hand, suggests that such costs might actually be large.

The analysis in this paper raises a broader question concerning the link between regulation and distrust. Aghion, Algan, Cahuc and Shleifer (2008) investigates this relationship between trust and regulation in general terms, looking at trust in government, in institutions, in competition, and looking at regulations in different markets and activities. The authors show and rationalize a key puzzle in the relation between regulation and distrust: individuals who distrust government tends to demand even more regulation. Aghion et al. (2008) also investigate the role of civil education in explaining the relation between distrust and regulation. 


\section{References}

[1] Acemoglu, A., Aghion, P., Lelarge, C., Van Reenen, J. and Zilibotti, F., 2007, Technology, Information and the Decentralization of the Firm, Quarterly Journal of Economics, 122, $1759-1800$.

[2] Akerlof, G., 1980, A Theory of Social Custom of Which Unemployment May Be One Consequence, Quarterly Journal of Economics 95, 749-775.

[3] Alesina, A and M. Angeletos, M. 2005, Fairness and Redistribution: US vs. Europe, American Economic Review, 95: 913-35.

[4] Aghion, P., Algan, Y., Cahuc, P. and Shleifer, A., 2008, Regulation and Distrust, mimeo Harvard.

[5] Algan, Y. and Cahuc, P., 2007, Social Attitudes and Economic Development: An Epidemiological Appraoch, Working Paper CEPR.

[6] Algan, Y. and Cahuc, P., 2006, Civic Attitudes and Labor Market Institutions, American Economic Journal, Forthcoming.

[7] Blanchard, O., and Philippon, T., 2006, The Quality of Labor Relations and Unemployment, MIT Working Paper 2006.

[8] Benabou, R., and Tirole, J., 2006, Belief in a Just World and Redistributive Politics, Quarterly Journal of Economics, 121(2), 699-746.

[9] Bisin, A, and Verdier, T. 2001, The Economics of Cultural Transmission and the Dynamics of Preferences,. Journal of Economic Theory, 97, 298-319.

[10] Booth, A., 1985, The Free Rider Problem and a Social Custom Model of Trade Union Membership, Quarterly Journal of Economics 100, 253-261.

[11] Booth, A. and M. Chatterji, 1993, Reputation, Membership and Wages in an Open Shop Trade Union, Oxford Economic Papers 45, 23-41.

[12] Checchi, D. and Lucifora, C., 2002, Union Density, the Economic Roles of Unions and Institutions, Economic Policy, vol 17(2), pp. 362-408.

[13] Corneo, G., 1995, Social Custom, Management Opposition and Trade Union Membership, European Economic Review 39, 275-292. 
[14] Crouch, C., 1993, Industrial Relations and European State Traditions. Clarendon Press, Oxford.

[15] Fernandez, R., 2007, Culture and Economics, New Palgrave Dictionary of Economics, 2nd edition, edited by Durlauf, S. and Blume, L., Palgrave Macmillan (Basingstoke and New York)

[16] Fernandez, R. and Fogli, A., 2005, Culture: An Empirical Investigation of Beliefs, Work, and Fertility, Federal Reserve Bank of Minneapolis, Research Department Staff Report 361.

[17] Freeman, R. and Medoff, J. 1984, What Do Unions Do?, New-York, Basic book.

[18] Guiso, L., Sapienza, P. and Zingales, L., 2004, The Role of Social Capital in Financial Development, American Economic Review, vol 94(3), pp. 526-556.

[19] Guiso, L., Sapienza, P. and Zingales, L., 2006, Does Culture Affect Economic Outcomes?, Journal of Economic Perspectives 20, 23-48.

[20] Guiso, L., Sapienza, P. and Zingales, L., 2007a, Long term persistence, Working Paper University of Chicago. .

[21] Guiso, L., Sapienza, P. and Zingales, L., 2007b, Social Capital as Good Culture, forthcoming, Journal of the European Economic Association.

[22] Hirshman, O., 1970, Exit, Voice, and Loyalty: Responses to Decline in Firms, Organizations, and States, Harvard University Press,

[23] Immervoll, H., 2007, Minimum Wages, Minimum Labour Costs and the Tax Treatment of Low-wage Employment, OECD Social Employment and Migration Working Papers 46, OECD Directorate for Employment, Labour and Social Affairs.

[24] Knack, S. and Keefer, P., 1997, Does Social Capital Have an Economic Payoff, A CrossCountry Comparison, Quarterly Journal of Economics, vol.112, pp. 1251-1288.

[25] La Porta, R., Lopez-de-Silvanes, F., Shleifer, A., and Vishny, R., 1997, Trust in Large Organizations, American Economic Review, vol 87, pp. 333-38.

[26] Lindbeck, A., and Nyberg, S., 2006, Raising Children to Work Hard: Altruism, Work Norms, and Social Insurance, The Quarterly Journal of Economics, vol. 121(4), pages 14731503 
[27] Lindbeck, A., Nyberg S., Weibull, J.W., 1999. Social Norms and Economic Incentives in the Welfare State, Quarterly Journal of Economics 114, 1-35.

[28] Naylor, R., 1989, Strikes, Free Riders, and Social Customs, Quarterly Journal of Economics 104, 771-785.

[29] Naylor, R. and M. Cripps, 1993, An Economic Theory of the Open Shop Trade Union, European Economic Review 37, 1599-1620.

[30] Naylor, R. and Raaum, O., 1993, The Open Shop Union, Wages and Management Opposition, Oxford Economic Papers 45, 589-604.

[31] Neumark, D. and Wascher, W., 2004, Minimum Wages, Labor Market Institutions and Youth Employment: A Cross-Sectional Analysis, Industrial and Labor Relations Review, vol. 57(2), 223-248.

[32] Nickell, S, Nunziata, L., Ochel, W. and Glenda Q., 2001, The Beveridge curve, Unemployment and Wages in OECD from the 1960s to the 1990s, LSE working paper $n^{\circ} 0502$.

[33] Ostrom, E., 2005, Policies That Crowd Out Reciprocity and Collective Action, in Gintis, H., Bowles, S., Boyd, R., Fehr, E., (eds), Moral Sentiments and Material Interests, MIT Press, chapter 9, pp. 253-275.

[34] Persson, T. and Tabellini, G., 2000, Political Economics, MIT Press.

[35] Piketty, T., 1995, Social Mobility and Redistributive Politics, Quarterly Journal of Economics $110,551-584$.

[36] Putnam, R., 1993, Making Democracy Work, Princeton University Press, Princeton, NJ.

[37] Putnam, R., 2000, Bowling Alone: The Collapse and Revival of American Community. New York: Simon and Schuster.

[38] Rice, T., and Feldman, J., 1997, Civic Culture and Democracy from Europe to America, Journal of Politics, pp. 1143-72.

[39] Tabellini, G., 2005, Culture and Institutions: Economic Development in the Regions of Europe, IGIER working paper $n^{\circ} 292$.

[40] Tabellini, G., 2007a, Institutions and Culture, Presidential lecture at the meeting of the European Economic Association, Budapest. 
[41] Tabellini, G., 2007b, The Scope of Cooperation: Norms and Incentives, mimeo, IGIER.

[42] Tocqueville, A., 1835, Democracy in America, Penguin Classics edition 2003. 


\section{A Appendix A: Typology of short run equilibria in the $\left(q_{t}, \bar{w}_{t}\right)$ plane}

Let us assume that $q_{t}=\operatorname{Pr}\left[e=c \mid h_{t}(n, s)\right]$ and $\bar{w}_{t}$ are exogenous.

From equations (2) and (4), we know that the measure of unionized workers is positive if and only if

$$
\begin{array}{ll}
1-\bar{w}_{t}-\frac{c}{\varepsilon}>0 & \text { when } i_{t}=0, \\
1-\bar{w}_{t}-\frac{c}{q_{t}(1-2 \varepsilon)+\varepsilon}>0 & \text { when } i_{t}=I .
\end{array}
$$

From equation (6) we know that there is investment in labor relations if and only if

$$
\Delta\left(\bar{w}_{t}, q_{t}\right)>I
$$

Since function $\Delta$ is decreasing with $\bar{w}$ and increasing with $q$, condition (A2) defines an area in the $\left(q_{t}, \bar{w}_{t}\right)$ plane whose frontier is upward sloping. There is positive investment for values of $\left(\bar{w}_{t}, q_{t}\right)$ above the frontier and no investment for values of $\left(\bar{w}_{t}, q_{t}\right)$ below the frontier.

For values of $\left(\bar{w}_{t}, q_{t}\right)$ below the frontier, there is zero investment and condition (A1) implies that the measure of unionized workers is positive if and only if $\bar{w}_{t}>1-\frac{c}{\varepsilon}$.

For values of $\left(\bar{w}_{t}, q_{t}\right)$ above the frontier, there is positive investment and (A1) implies that the measure of unionized workers is positive if and only if $\bar{w}_{t}>1-\frac{c}{q_{t}(1-2 \varepsilon)+\varepsilon}$. Since it turns out that

$$
\Delta\left(1-\frac{c}{q_{t}(1-2 \varepsilon)+\varepsilon}, q_{t}\right)=0
$$

union density is necessarily positive for values of $\left(\bar{w}_{t}, q_{t}\right)$ compatible with positive investment.

\section{B Appendix B: Investment in cooperation and the quality of labor relations}

This section documents on the relationship between unions' investment in cooperation and the quality of labor relations. The model predicts a strongly positive correlation between the two. We measure the investment in cooperation by using two main indicators. The first indicator is the degree of workplace presence of unions. The workplace appears indeed to be the main location for service provision to union members and for providing protection and support during the negotiation with management. Strong workplace representation thus directly affects the benefits from union membership and also the extent to which voice and cooperation prevail over exit in labor relations. We measure the workplace presence of unions by using the indicator of Checchi and Lucifora (2002) for the 1990s. The indicator ranges from 0 to 1 , with a higher score suggesting a higher representation of unions in all workplaces. The second indicator of investment in cooperation is the degree to which unions try to coordinate and centralize 
their decisions. We expect that beliefs in cooperation and union membership are higher wherever unions have been able to create and defend centralized institutions of collective bargaining with employers. We measure this using the coordination index of Checchi and Lucifora (2002) for the 1990s. The index combines information about the degree of centralization in wage bargaining and wage coordination across the main workers unions, on a quinquennial base. The indicator include two vertical and horizontal dimensions in negotiations. The vertical dimension captures how bargaining is divided between different levels (national, industry, firm) within a union confederation. The horizontal dimension captures the number of union confederations. The index is ranked between 0 and 1 , a higher score indicating a greater level of centralization/coordination. According to this criteria, France has a low score because workers union confederations are highly divided and enterprise bargaining has greater importance than sectorial and national bargaining. In contrast, Nordic countries have a much greater score. This is not necessarily due to more centralization, since a trend towards decentralization has occurred in these countries since the eighties. But the degree of coordination between unions confederations is much greater compared to other countries.

Figure 12 reports the correlation between the indicator of workplace presence of unions and the perceived quality of labor relations measured by the Global Competitiveness Reports 1999. Figure 13 reports the same correlation pattern between the quality of labor relations and the degree of coordination and centralization of negotiations between trade unions. In both cases, steady positive correlations show up, suggesting that the quality of labor cooperation is strongly associated with investment in cooperation by unions. Approximately 40-50 percent of the cross-country heterogeneity in the quality of labor relations could be associated with differences in the unions' efforts to be present in firms locally and to coordinate and centralize negotiations nationally.

\section{Appendix C: Minimum wage regulations in OECD countries}

The data on minimum wages come from the OECD database and Neumark and Wascher (2004) for the levels, and from the International Labor Organization (ILO) for the legislation.

- Minimum wage legislations

The legislation differs mainly depending on the existence of a legal statutory minimum wages, and the dispersion of minimum wages. These distinctions are documented below.

1. Method of setting

We first measure the extent to which minimum wages are directly set by law or by collectively agreed minimum wages negotiated between social partners. Column 2 of table 8 indicates whether wage 


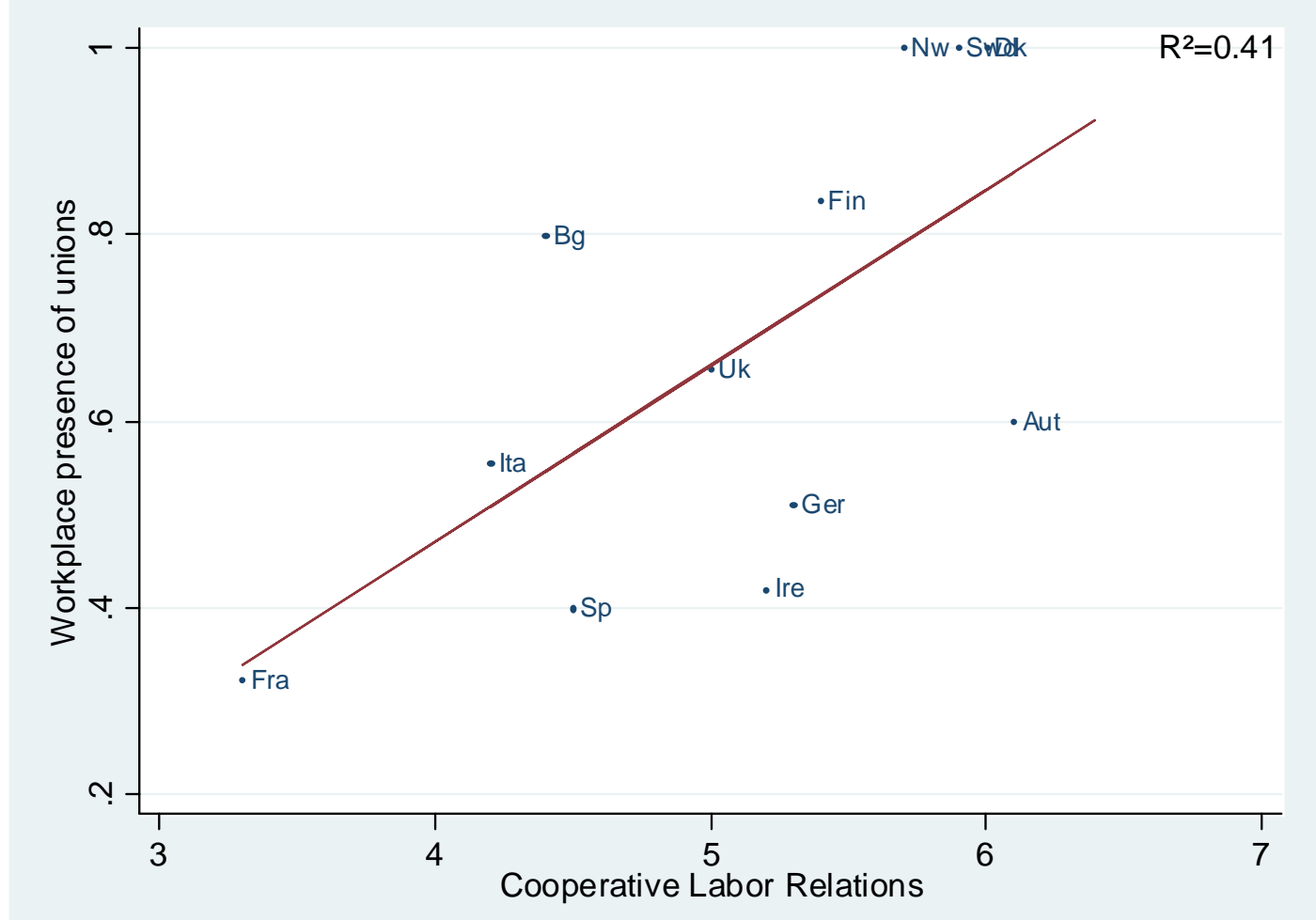

Figure 12: Correlation between the workplace presence of unions and the quality of labor relations. Sources: Checchi and Lucifora (2002) and CGR (1999). 


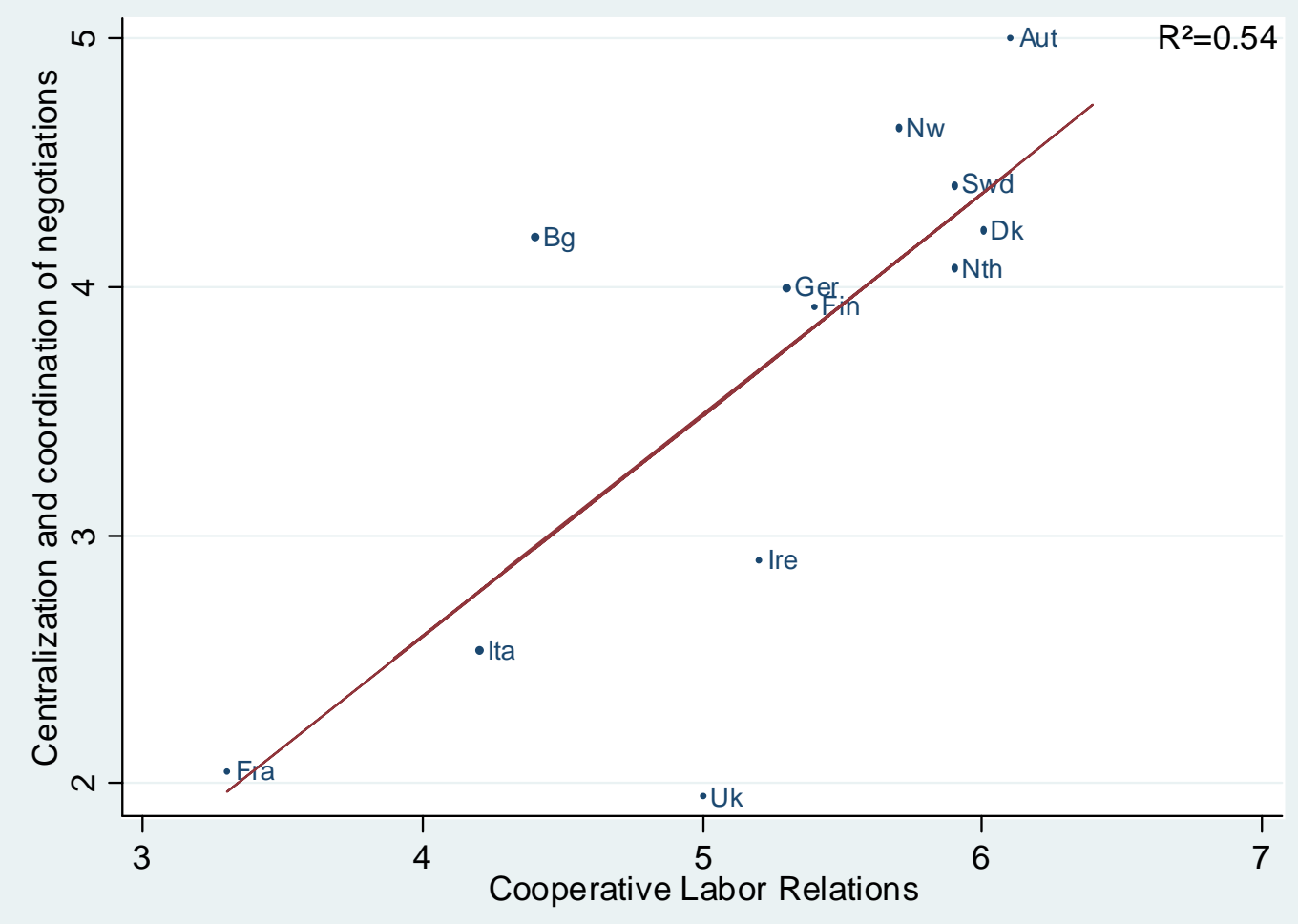

Figure 13: Correlation between the centralization and coordination of negotiation and the quality of labor relations. Sources: Checchi and Lucifora (2002) and CGR (1999). 
floors are set by statutory rules defined by the law or by collective negotiation. Column 3 of table 8 indicates the coverage of the minimum wage. This coverage is equal to one when the minimum wage is set by law. However, it can be smaller than one when there is no statutory minimum wage. In some countries the wage floor is negotiated at the sectorial level, but it is automatically extended in other countries. As a matter of fact, the coverage rates of collectively agreed minimum wage reach 70 percent in Norway, 80 percent in Sweden 81 percent in Denmark while they are equal to 99 percent in Austria and Italy. Eventually, almost all Anglo-Saxon countries have a statutory minimum wage. The United States recognized a statutory wage floor in 1938 by the Fair Act while United Kingdom established a national minimum wage in 1999 after having abolished the system of Wage Councils in 1993.

Table 8: Method of wage setting. Source: ILO.

\begin{tabular}{lll}
\hline \hline & Determination & Coverage \\
\hline Australia & Statutory, Provincial level & 1 \\
Austria & Negotiation, National extension & .9 \\
Belgium & Negotiation, National level & 1 \\
Canada & Statutory, Federal and provincial levels & 1 \\
Czr & Statutory, National level & 1 \\
Denmark & Negotiation, Industry level & $0.8-0.9$ \\
Finland & Negotiation, Industry level & 0.9 \\
France & Statutory, National level & 1 \\
Germany & Negotiation, National extension & 0.9 \\
Greece & Statutory, National level & 1 \\
Hg & Statutory, National level & 1 \\
Italy & Negotiation, National extension & 1 \\
Japan & Statutory, Prefectures & 1 \\
Mexico & Statutory, National & 1 \\
Netherlands & Statutory, National & 1 \\
Norway & Negotiation, Industry level & 0.7 \\
Poland & Statutory, National & 1 \\
Portugal & Statutory, National & 1 \\
Spain & Statutory, National & 1 \\
Sweden & Negotiation, Industry level & 1 \\
Turkey & Statutory, National & 1 \\
Uk & Negotiation, industries, Statutory, 1999 & 1 \\
Usa & Statutory, Federal, States & 1 \\
\hline
\end{tabular}

2. Variation in wage floors

Wage floors can vary in five main dimensions: age, qualification, regions, sectors and occupations. Tables 9 indicates whether the minimum wage is set at the national level. It shows that most 
countries with a statutory minimum wage opt to set a single wage at the national level. Exceptions are Canada and the United States which sets minimum wages at both the federal and the regional level. In the United States, some States, mainly in the South, do not implement the Federal law and others set the minimum wage above the federal floor. In Canada, each province sets its own minimum wage, leading to a wide gap in statutory minimum wages. In Japan, the minimum wage is set at the prefecture level, with some different wages for different industries in a given prefecture. Mexico lies in between, the minimum wage being set at the regional level, but with only three broad regions and a quite narrow gap between different regional levels.

We also report the potential existence of sub-minimum rates for young workers and trainees. Such sub-minimum rates are quite common in OECD countries since they concern around half of them. Countries which exclude such provisions are: Czech Republic, Greece, Hungary, Japan and Mexico. But significant differences exist among countries authorizing sub-minimum wage provisions. The first difference lies in the range of ages covered by the provision. Basically provisions would extend until 24 years old in Sweden or 22 years in Netherlands while such reductions are permitted only for workers younger than 17 years in France and 18 years in Ireland. The second difference is the extent of reductions. United-Kingdom stands as a polar case with no minimum wage for people younger than 21 years. The Netherlands accepts a reduction up to 40 percent of standard minimum wage at 17 years old while the wage floor is set at 80 percent of the standard minim wage in France or Spain for this age.

\section{- Minimum wage levels}

The level of the minimum wages measured by the OECD refers in general to a full-time workers in the industry. The data for countries without statutory minimum wage floors correspond to the same definition, borrowed from Neumark and Wascher (2004).

\section{Australia}

The federal minimum weekly wage divided by the median gross weekly earnings of full-time workers. Prior to 1997, the federal minimum is extrapolated based on Metal Industry Award C14 wages and National Wage Case decisions. Source: OECD Minimum Wage Database. Method of setting: An independent Commission (Australian Industrial Relations Commission or AIRC) is responsible for setting the federal minimum wage via an annual Safety Net Review. Although some state-level legislation also exists, the federal minimum wage is applicable to the majority of Australian workers. Other provisions: 
Table 9: Variations in wage-setting. Source: ILO.

\begin{tabular}{lll}
\hline \hline & Variations by: & Subminimum (Age limits, \% of standard minimum wage) \\
\hline Australia & Industries, Regions, Occupation, Age & \\
Austria & Industries, Occupation, Age & No \\
& & $20: 94 \%, 19: 88 \%, 18: 82 \%$ \\
Belgium & Age & $17: 76 \%,<17: 70 \%$ \\
& & No \\
Canada & Industries, regions,occupations & No \\
Czr & Occupation & $<18: 40 \%$ \\
Denmark & Industry, Age & No \\
Finland & Industries, Age, Occupations & $17: 90 \%,<17: 80 \%$ \\
France & Age & Trainees \\
Germany & Region, Age, Qualifications & No \\
Greece & Age, Marital status, Qualifications & No \\
Hg & No & Trainees \\
Italy & Industry, Age & No \\
Japan & Industry, Age, Occupation & No \\
Mexico & No & $22: 85 \%, 21: 72,5 \%, 20: 61,5 \%, 19: 52,5 \%$, \\
& & $18: 45,5 \%, 17: 39,5 \%, 16: 34,5 \%, 15: 30 \%$ \\
Netherlands & Age & No \\
Norway & Industry, age, Occupation & No \\
Poland & No & $<18: 75 \%$ \\
Portugal & Age & $<18: 89 \%$, suppressed in 1998 \\
Spain & Age & $<24: 89 \%$ \\
Sweden & Industry,Age, Occupation & $<16: 85 \%$ \\
Turkey & Age & $<21: 0 \%$, Change in 1999 \\
Uk & Industry,Age & No \\
Usa & Age, Job tenure & \\
\hline & &
\end{tabular}




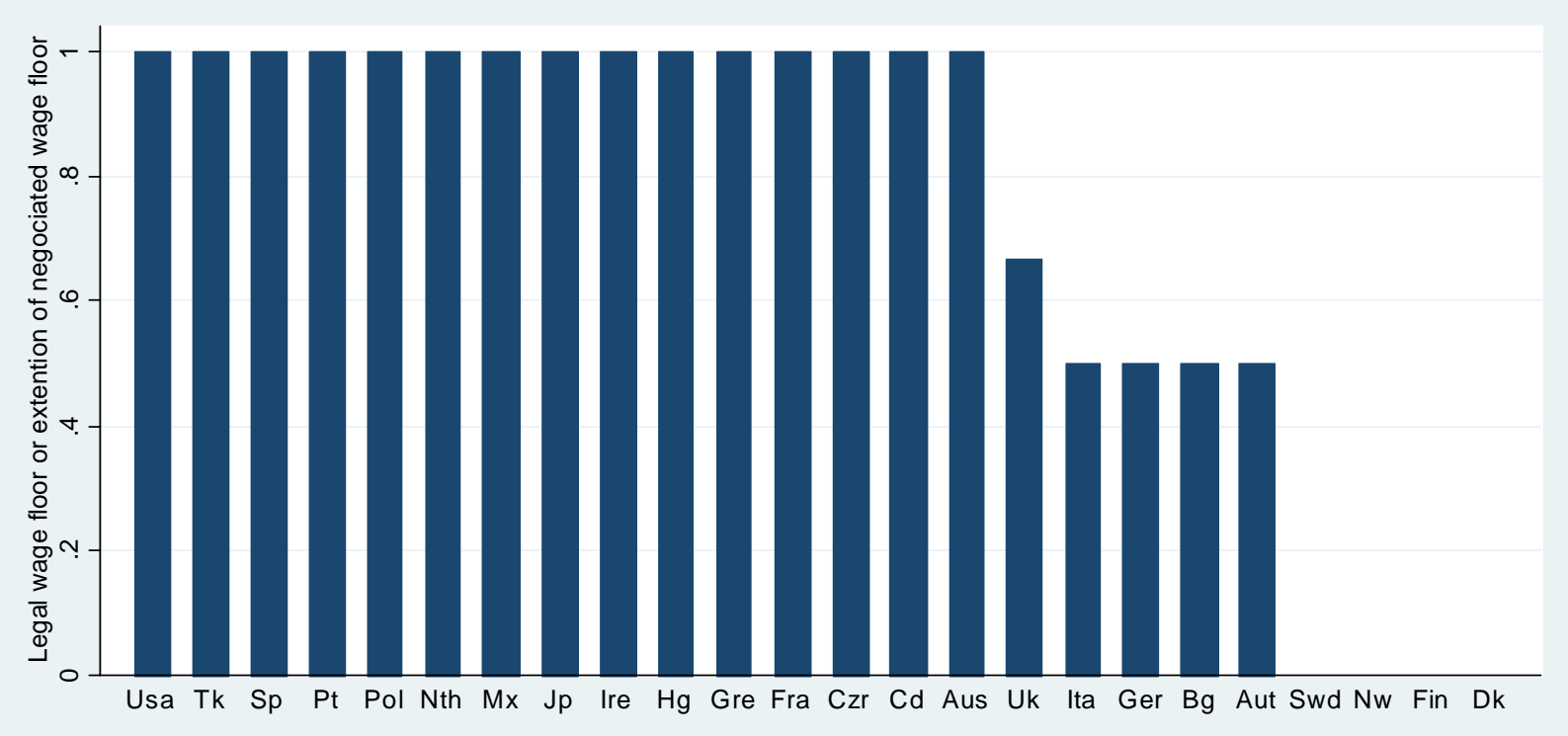

Figure 14:

Minimum wages may differ by industry and occupation if the AIRC approves applications to vary minimum award rates from the federal level. There is also a youth subminimum, with rates ranging from 40 percent to 85 percent of the adult minimum depending on age.

\section{Belgium}

The minimum monthly wage for workers aged 21 and over divided by the median gross monthly earnings of full-time workers. Source: OECD Minimum Wage Database. Method of setting: The privatesector minimum wage (Revenue Minimum Mensuel Moyen Garanti) is set via a biennial national collective bargaining agreement between social partners (employers and unions) within the Conseil National du Travail. This minimum wage is then made mandatory for the entire private sector by royal decree. Between collective bargaining agreements, the minimum wage is indexed to the consumer price index, with a formula that adjusts up the minimum two months following a cumulative 2 percent increase in the CPI. Other provisions: The laws provide for a subminimum wage for employees less than 21 years of age. This subminimum wage is 70 percent of the adult minimum for employees aged 16 or under, with the proportion rising by 6 percentage points for each extra year of age.

\section{Canada}

Weighted average of provincial hourly minimum wage levels (weighted by the size of the labor force in each province) divided by median gross hourly earnings of full-time workers. Source: OECD Minimum Wage Database. Method of setting: Minimum wages are set separately in each province and territory 
either by minimum wage boards or by the Lieutenant-Governor in Council. Other provisions: In most provinces, a single minimum wage applies to workers aged 16 and over. An exception is Ontario, which allows a slightly lower minimum wage rate to be paid to students under 18 years of age.

\section{Denmark}

The average hourly minimum wage divided by an average hourly wage. Source: Dolado, et al. (1996). Method of setting: There is no legally-mandated national minimum wage. Instead, minimum hourly wage rates are set via centralized industry-level collective bargaining agreements, which may be supplemented by agreements at the plant level. Other provisions: Minimum wages may vary considerably at the industry level. In addition, workers under 18 years of age are generally subject to a lower minimum wage.

Finland

Average monthly minimum wage divided by an average monthly wage. Source: Dolado, et al. (1996). Method of setting: There is no legislated national minimum wage. Instead, minimum wage rates are set via centralized industry-level collective bargaining agreements. The law requires all employers (including non-union employers) to pay the minimum rates contained in these collective bargaining agreements. Other provisions: Minimum wages may vary considerably at the industry level.

\section{France}

Gross annual equivalent of the annual minimum wage divided by median gross annual earnings of full-time workers in the private and semi-private sector. Source: OECD Minimum Wage Database. Method of setting: The minimum wage (Salaire Minimum Interprofessional de Croissance, or SMIC) is set by the government. Administrative procedures are used to adjust the SMIC each July to reflect both consumer price increases and real wage increases in the hourly wages of manual workers. In addition, the government has sometimes enacted additional increases in the minimum wage. Other provisions: Limited youth subminimum wage rates are applicable to workers under the age of 18 . Specifically, workers aged 16 can be paid 80 percent of the adult minimum, while workers aged 17 can be paid 90 percent of the adult minimum for six months.

\section{Germany}

Average monthly minimum wage divided by an average monthly wage. Source: Dolado, et al. (1996). Method of setting: There is no legislated national minimum wage. Instead, minimum wage rates are set via industry-specific collective bargaining agreements. These agreements can be extended to all employers in the industry if the workforce of the employers directly affected by the agreement comprises at least 50 percent of the total workforce in that industry. In addition, the government may call for a Hauptausschu $\beta$ commission (consisting of the government, employers, and employees) to set minimum wage levels in industries where unions represent only a minority of employees. Other provisions: Minimum 
wages may vary considerably at the industry level. Some industry agreements include youth subminimum wage rates.

\section{Greece}

Minimum daily wage for an unqualified single worker with no work experience (converted to an hourly rate by assuming an 8 hour work day) divided by the mean hourly wage in manufacturing. Source: OECD Minimum Wage Database. Method of setting: The national minimum wage level is negotiated annually by representatives of the General Confederation of Greek Workers and the main employer organizations (facilitated by arbitration if necessary). The negotiated level is routinely ratified by the Ministry of Labor and is applicable to all workers. Other provisions: The minimum wage varies slightly by tenure and by marital status.

Ireland

Minimum gross hourly wage divided by median weekly earnings of full-time employees (converted to an hourly rate). Source: OECD Minimum Wage Database. Method of setting: The government enacted a national minimum wage in April 2000. This minimum wage is reviewed annually by the independent Low Pay Commission, which then recommends an increase for consideration by the government. Prior to that legislation, statutory minimum wages were set by Joint Labour Committees in a limited number of lowwage industries. These Labour Committees consisted of equal numbers of representatives of employers and workers appointed by the Labour Court and a chairman appointed by the Minister for Enterprise, Trade, and Employment. Other provisions: Under current law, workers under the age of 18 can be paid 70 percent of the adult minimum wage.

Italy

Average minimum monthly wage divided by an average wage. Source: Dolado, et al. (1996). Method of setting: There is no legislated national minimum wage. Instead, minimum wage rates typically are set via industry-specific national collective bargaining agreements, which then are applicable to all workers in the industry. Other provisions: Minimum wages may vary considerably at the industry level. Some industry agreements include youth subminimum wage rates. Japan Definition of minimum wage variable: Weighted average of prefectural hourly minimum wage levels (weighted by the size of the labor force in each prefect) divided by median gross monthly earnings (converted to hourly basis using average monthly hours worked). Source: OECD Minimum Wage Database.

\section{Netherlands}

Minimum weekly earnings for persons aged 23 to 64 divided by median gross annual earnings of full-time employees (divided by 52). Source: OECD Minimum Wage Database. Method of setting: The minimum wage (Minimumloon) is set by law and is normally updated in January and July of each year 
based on the average increase in wages negotiated in the private sector. The government may choose to suspend or alter the increase if the unemployment rate is above a certain level. Other provisions: The laws provide for a subminimum wage for employees less than 23 years of age. This subminimum wage ranges from $85 \%$ of the adult minimum for employees aged 22 to 30 percent for those less than 17 .

Norway

Average minimum hourly wage divided by an average wage. Source: Dolado, et al. (1996).

Method of setting: There is no legislated national minimum wage. Instead, minimum wage rates typically are set via industry-specific national collective bargaining agreements, which can then be extended to cover all workers in the industry. Other provisions: Minimum wages may vary considerably at the industry level.

Portugal

Minimum monthly wage for nonagricultural workers aged 20 and over divided by median gross annual earnings of full-time workers (divided by 12). Source: OECD Minimum Wage Database. Method of setting: The minimum wage (Salário Minimo Nacional) is set annually by the government after consultation with the Permanent Commission for Social Cooperation. Other provisions: Under current law, workers under the age of 18 can be paid $75 \%$ of the adult minimum wage. Prior to 1987, workers aged 18 and 19 were also eligible for subminimum wage rates.

\section{Spain}

Minimum monthly wage for workers aged 18 and over divided by median gross annual earnings of full-time workers (divided by 12). Source: OECD Minimum Wage Database. Method of setting: The minimum wage (Salario Minimo Interprofesional) is set annually by government decree, with the amount of any increase determined by the Council of Ministers. Other provisions: Under current law, all workers aged 16 and over are subject to the adult minimum wage. Prior to 1999, workers under the age of 18 could be paid less than the adult minimum wage.

Sweden

The average hourly minimum wage divided by an average hourly wage. Source: Dolado, et al. (1996). Method of setting: There is no legislated national minimum wage. Instead, minimum wage rates typically are set via industry-specific national collective bargaining agreements, which then are applicable to all workers in the industry. Other provisions: Private sector agreements typically specify separate minimum wage rates for adult workers (ages 24 and above) and youths.

\section{United Kingdom}

Beginning in 1999, national hourly minimum wage divided by median hourly earnings of full-time adult employees. Source: OECD Minimum Wage Database. Prior to 1993, the average minimum wage 
in Wages Council sectors divided by an average wage. Source: Dolado, et al. (1996). There was no minimum wage from August 1993 through March 1999. Method of setting: Under current law, minimum wage levels are reviewed regularly based on recommendations from the independent Low Pay Commission. Prior to 1993, minimum wages were set in 25 certain industries by Wage Councils, which were originally set up to protect low-wage workers who were not covered by collective bargaining agreements. Other provisions: Under current law, workers aged 18 to 21 may be paid about 85 percent of the current adult minimum wage; workers under age 18 are exempt from the minimum wage. Prior to 1993, minimum wage rates differed substantially by industry, age, and region. Beginning in 1986, all workers under age 21 were exempt from minimum wage laws.

\section{United States}

Federal minimum hourly wage divided by median usual weekly earnings of full-time employees (converted to an hourly rate by assuming a 40 hour full-time workweek). Source: OECD Minimum Wage Database. Method of setting: The national minimum wage level is set by the government and can only be updated by legislative action. Other provisions: States have the ability to set a minimum wage above the federal level. Subminimum wage rates may be paid to selected full-time students and newly-hired youths (for 90 days). 


\section{Appendix D: Minimum wages and union densities in the United States}
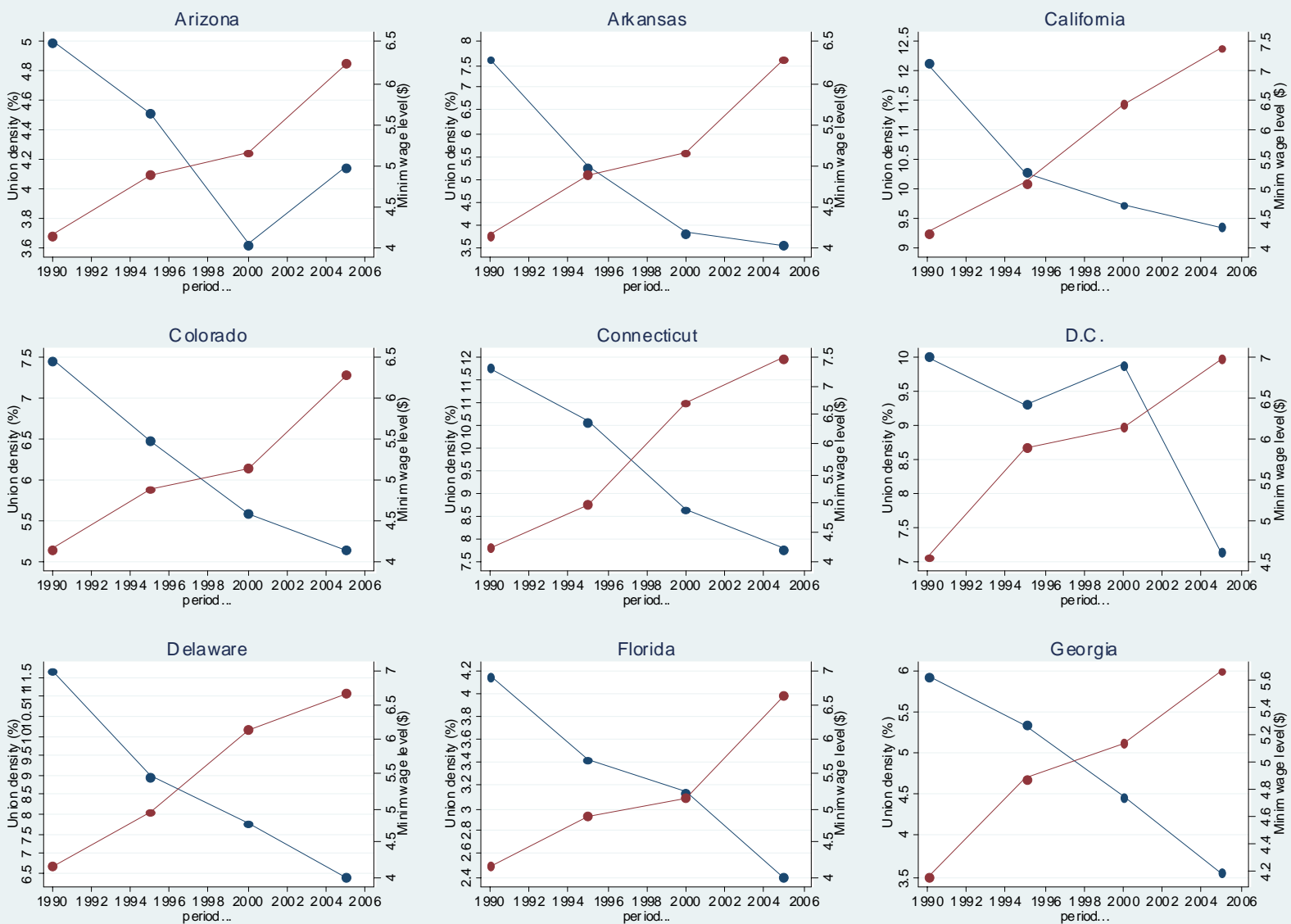

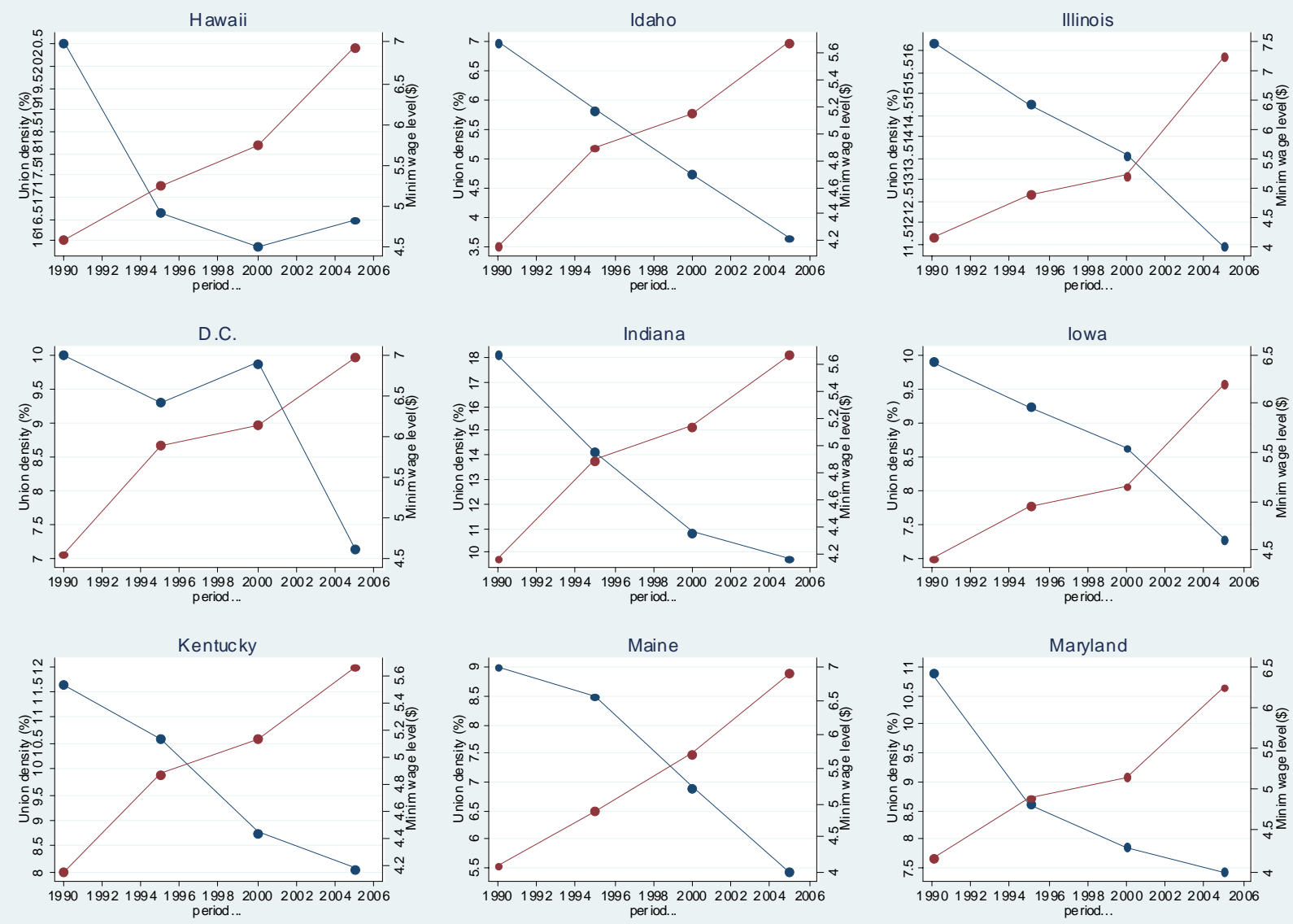

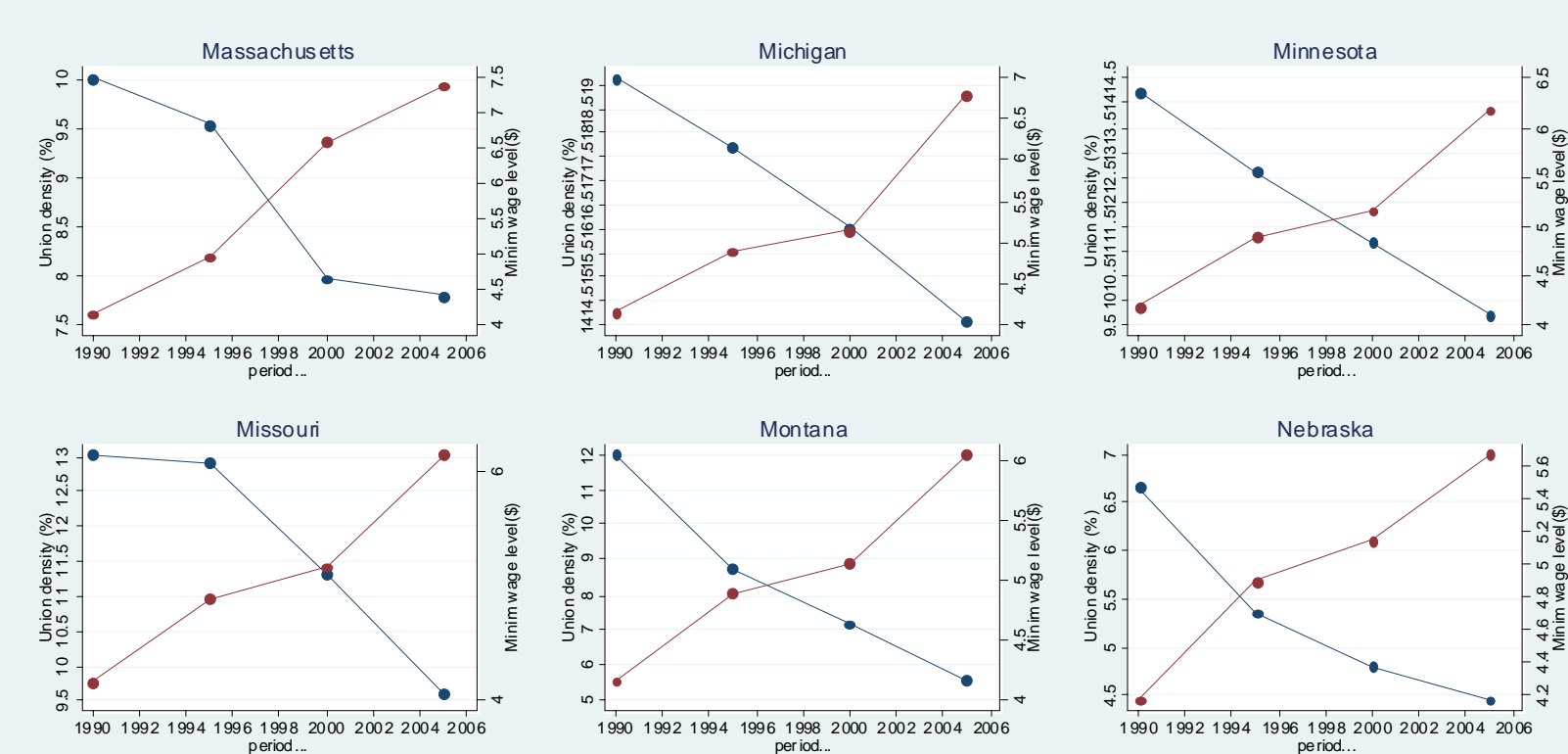

Nebraska

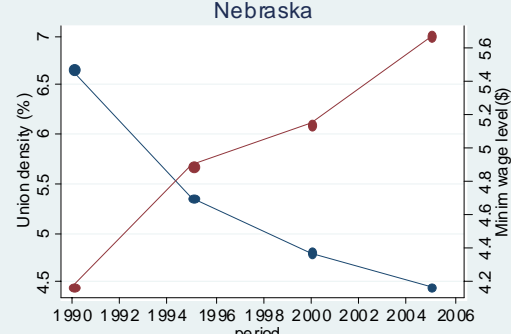

tevada

period...
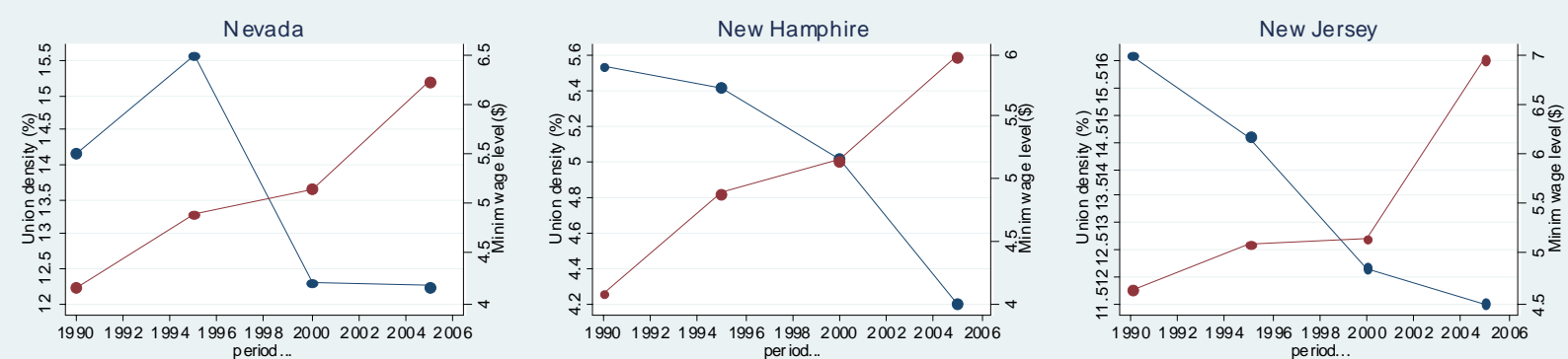


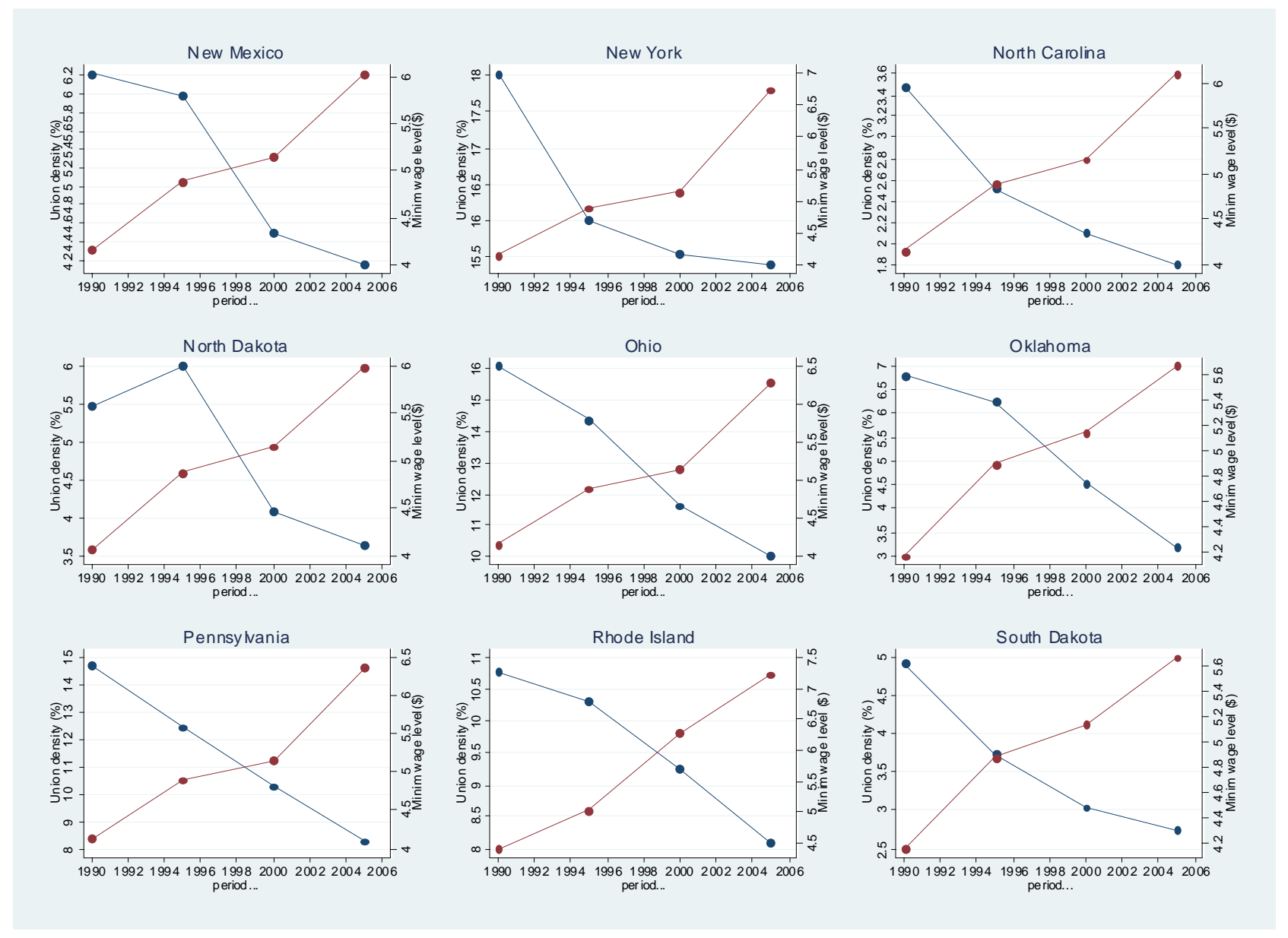




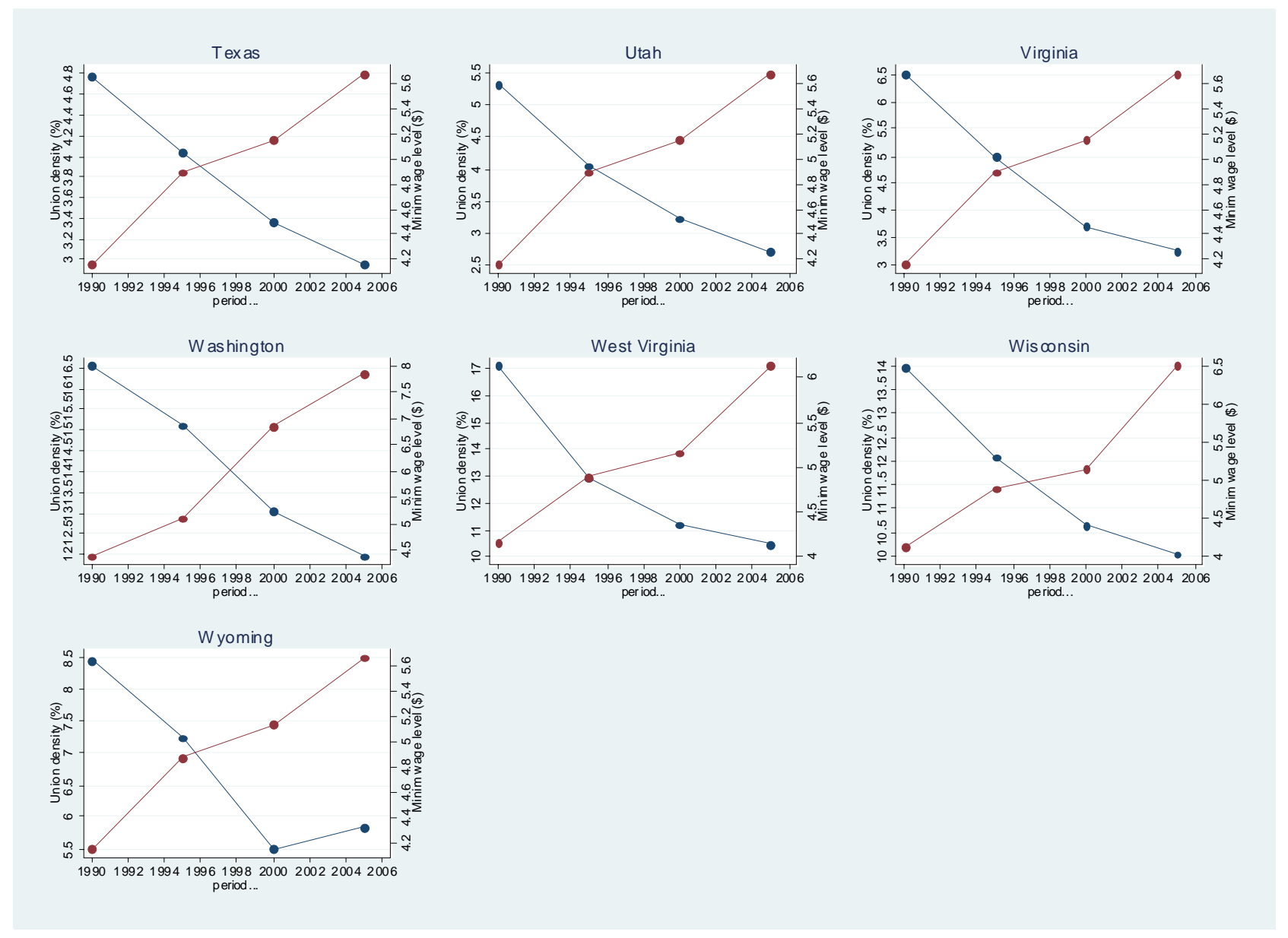

